\title{
Segunda gira del teósofo Jinarajadasa a América Latina, 1938. Análisis de sus conferencias y otros ensayos
}

\section{Second Tour of the Theosophist Jinarajadasa to Latin America, 1938. An analysis of his conferences and other essays}

\author{
Otto German Mejía Burgos \\ Universidad Centroamericana “José Simeón Cañas”, El Salvador \\ ottogmb7@,hotmail.com
}

Recepción: 11 de enero de 2018/Aceptación: 28 de marzo de 2018.

doi: https://doi.org/10.15517/rehmlac.v10i1.31970

Palabras clave

Dios; Cristo; platonismo; intuición; reencarnación.

Keywords

God; Christ; Platonism; Intuition; Reincarnation.

Resumen

En este artículo se aborda las íntimas relaciones que se dieron entre sociedades teosóficas, opinión pública, gobierno salvadoreño y figuras mundiales de la teosofía, sectores que más allá de las discrepancias políticas, estuvieron interconectados por una misma tendencia esotérica: la teosofía. Además, la presente explica la reacción de los periódicos salvadoreños ante la segunda visita de Jinarajadasa a Latinoamérica y al Caribe a través de sus conferencias y de los distintos artículos que se escribieron en razón de tan trascendental acontecimiento.

\section{Abstract}

This article describes the close relationship between theosophical societies, public opinion, Salvadorian Government and world theosophy's figures. These sectors in spite of their political differences were interconnected under the same esoteric tendency: theosophy. We also, explain the Salvadorian newspapers' reaction upon Jinarajadasa's second visit to Latin America and the Caribbean, analyzing some of his conferences as well as different articles published on the occasion of such a transcendental event.

\section{Introducción}

Este ensayo aborda la segunda gira que Jinarajadasa realizó por Latinoamérica en el año de 1938. Tiene como objetivo fundamental desarrollar y analizar los distintos discursos que el teósofo dictó en todo el continente, pero haciendo especial énfasis en su impacto en tierras cuscatlecas y centroamericanas. Además muestra las acciones tanto de la prensa nacional como de las logias autóctonas a fin de organizar su recibimiento y estadía. Es 
obvio advertir que todo este ambiente propicio a la teosofía ${ }^{1}$ demostraría que dicha tendencia, muy invisibilizada por los estudios académicos actuales, tuvo una connotación de muy amplios alcances que aún no es posible precisar y valorar de manera adecuada.

Respaldamos dicha aseveración en el hecho de que hasta el momento Marta Casaús Arzú no ha elaborado un estudio exhaustivo donde analice a profundidad la enorme relevancia que tuvo la segunda gira de Jinarajadasa por el continente más allá de algunas menciones esporádicas. Ahora bien, la académica también alude a que hubo ciertos viajeros extranjeros como Jinarajadasa que ayudaron a conformar redes intelectuales teosóficas de gran extensión en Centroamérica, pero de nuevo sin realizar un mayor examen ${ }^{2}$. Esto podría deberse a que a la autora lo que le interesa, en realidad, es desarrollar el pensamiento de Alberto Masferrer teniendo a Jinarajadasa como una de sus influencias lejanas ${ }^{3}$. En este sentido el mismo Masferrer hizo un breve comentario sobre Jinarajadasa en uno de sus artículos - estableciendo- que su pensamiento tenía ciertos puntos de contacto con la obra El Minimum Vital ${ }^{4}$.

De manera similar pasa con Rafael Lara-Martínez quien en su obra Del silencio y del olvido o los espectros del patriarca de manera muy aislada señala que Jinarajadasa visitó El Salvador en $1929^{5}$ y es que al antropólogo no le interesa tanto desentrañar el pensamiento esotérico predominante durante la época sino la política de la cultura indigenista de inspiración teosófica desarrollada durante la presidencia de Hernández Martínez y quizá la hibridación entre teosofía e indigenismo que aparece en la obra de Salarrué.

Esteban Rodríguez Dobles sigue este mismo enfoque estableciendo que a partir de la primera visita de Jinarajadasa a la región se articularon ciertas redes intelectuales y que su presencia contribuyó a la organización de ciertas logias, incluso, menciona que en

\footnotetext{
${ }^{1}$ Otto German Mejía Burgos, "La teosofía en algunos periódicos salvadoreños y centroamericanos durante las décadas de 1930 y 1940", REHMLAC 9, no. 2, (diciembre 2017-abril 2018): 232, https://revistas.ucr.ac.cr/index.php/rehmlac/article/download/30538/31664. Jinarajadasa define teosofía de la siguiente manera: "Es una exposición de hechos referentes al hombre, a la naturaleza y a Dios, descubiertos por los sabios de las generaciones pasadas y presentes por medio del método científico".

${ }^{2}$ Eduardo Devés Valdés, "Redes teosóficas y pensadores políticos latinoamericanos, 1910-1930", Cuadernos Americanos 6, no. 78, (1999): 137. Devés explica que "De hecho entre fines del siglo XIX y 1930, pero también después, se desarrolla entre nuestros intelectuales (poetas primero, educadores y pensadores después, políticos incluso) un movimiento espiritualista donde se combinan elementos teosóficos con hinduismo, reivindicación de lo oriental y en ocasiones, creencias o prácticas espiritistas. Esta sensibilidad teosóficooriental impregnó buena parte del quehacer intelectual y político".

${ }^{3}$ Marta Elena Casaús Arzú, El libro de la vida de Alberto Masferrer y otros escritos vitalistas, Edición crítica de la obra teosófico-vitalista (1927-1932) (Ciudad de Guatemala: F\&G Editores, 2012), 2.

${ }_{5}^{4}$ Patria, "Krishnamurtismo", 20 de junio de 1929, 1 y 5.

${ }^{5}$ Rafael Lara-Martínez Del silencio y del olvido o los espectros del patriarca (San Salvador: Fundación AccesArte, 2013), 221.
} 
Nicaragua se fundó una con su nombre ${ }^{6}$. Ahora bien, el factor común en todos estos trabajos es tomar a Jinarajadasa solamente como un parámetro de referencia marginal para referirse a otros temas de interés y no como un objeto de estudio central. Si nos ubicamos propiamente en El Salvador el panorama se vuelve más árido aun ya que en la academia nacional los estudios sobre esoterismo casi no han sido cultivados y los pocos que existen se centran en Masferrer.

En base a lo anterior habría que comenzar por decir que Jinarajadasa además de El Salvador en octubre de $1938^{7}$, también visitó Guatemala, Nicaragua, Costa Rica, Honduras y Panamá. El viaje inició en el puerto de La Guaira en Venezuela en donde tomó el tren que lo trajo a Centroamérica; a nivel de América Latina inició sus conferencias en Brasil después de visitar Portugal, país al cual llegó procedente de la India inglesa en donde inició su gira el 2 de enero de ese mismo año, aunque no pudo visitar España como él lo había previsto. Su estadía en Brasil fue durante el mes de febrero, -según sus mismas palabras-, era el país del continente que más le interesaba conocer, ya que sería ahí donde reencarnaría en su próxima vida ${ }^{8}$.

Vale decir que el gobierno de Brasil le presentó su moderno sistema de enseñanza para niños adaptado al sistema Montessori, creado precisamente por la teósofa María Montessori que, para esa época, era el más aceptado en ese país. Jinarajadasa creía que uno de los nuevos fundamentos a implementar en la escuela radicaba en el intuicionismo que intentaba derogar el antiguo régimen de enseñanza, de lo cual también se dará cuenta en este artículo. Después de Brasil conferenció en las capitales de Uruguay, Paraguay, Argentina, Chile, Perú, Bolivia, Colombia y Venezuela ${ }^{9}$. Luego de visitar Suramérica partió para México y seguidamente visitó algunos países del Caribe dentro de los cuales se encontraban: Cuba, Jamaica, Puerto Rico, Santo Domingo y Haití ${ }^{10}$.

Es importante destacar que tal y como lo señala Marta Casaús los congresos internacionales funcionaron como mecanismos de ampliación y difusión de todas estas nuevas ideas que circulaban con bastante fluidez y que se querían implementar en América,

\footnotetext{
${ }^{6}$ Esteban Rodríguez-Dobles, "Redes esotéricas en Centroamérica y Colombia (1904-1940). El caso de la

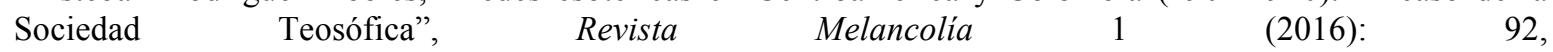
http://www.revistamelancolia.com/index.php/melancolia/article/view/5/5

${ }^{7}$ Diario de Occidente, "También visitará la República de Honduras el doctor Jinarajadasa", 20 de agosto de 1938,3 y 7.

${ }^{8}$ El Cronista, "Vendrá a Honduras el Dr. Jinarajadasa", 10 de agosto de 1938, 1 y 8.

${ }^{9}$ El Cronista, "Vendrá a Honduras el Dr. Jinarajadasa", 1 y 8 . Habría que señalar que en un principio, no tenía pensado visitar Bolivia, Perú y Venezuela por ser países que se consideraba ignoraban la importancia de los estudios teosóficos, pero al parecer algunos estudiantes de teosofía de esos países le solicitaron su presencia, a lo cual él accedió. Lo relevante de este dato, es que por este cambio en el itinerario acortó su presencia en cada república centroamericana.

${ }^{10}$ Osberto Wyld Ospina, "Personalidades que nos visitarán”, El Liberal Progresista, 26 de octubre de 1938, 3 y 7.
} 
Europa y Asía ${ }^{11}$. El nombre de las cinco conferencias fueron las siguientes: 1) "La teosofía y el destino de la humanidad", 2) "Los niños instrumentos (o agentes) de Dios", 3) "La nueva humanidad de la intuición", 4) "Principios de belleza" y 5) "La ciencia y la mente divina" 12 . Es preciso aclarar que estas últimas dos conferencias no aparecieron publicadas en ninguno de los periódicos que se consultó para esta investigación, lo cual no quiere decir que no tuvieron lugar sino que fueron de carácter "restringido", es decir, sólo se pudo asistir a ellas mediante invitación personal por tarjeta y su divulgación fue vedada al público en general ${ }^{13}$.

Ahora bien, también se han incluido los siguientes ensayos: "El crecimiento del alma a través del proceso de reencarnación", "Lo que es y lo que debe ser (a Platón y a Plotino)" y una conferencia titulada "Un mundo angustiado" donde Jinarajadasa planteó la difícil situación que se venía viviendo alrededor del mundo a partir de la depresión económica de 1929 y cuyos efectos devastadores perduraron durante gran parte de la década de los treinta. Se advierte que aunque no formaron parte del ciclo de conferencias que Jinarajadasa dictó en 1938, aparecieron como estudios complementarios en los distintos periódicos de El Salvador, con lo cual se dio la construcción de un entramado de concepciones teosóficas que se esparcieron como nunca antes en la historia del país y que evidentemente formaban parte de un proyecto de nación espiritualista que se quería implementar, auspiciado tanto por el Estado como por intelectuales, miembros de logias teosóficas y ciudadanía en general.

Finalmente habría que explicar que el término "esotérico" actualmente tiene muchos significados y muchas variantes, por lo que se hace conveniente dilucidar antes de iniciar con nuestro análisis que es lo que se entenderá por dicho concepto. Desde el punto de vista del desarrollo de la teosofía occidental se entenderá como un conocimiento de carácter religioso, mágico y sobrenatural que contara con una gran influencia del neoplatonismo propio de los movimientos espiritualistas del siglo XX y que será cultivado por ciertos grupos de personas autoproclamadas así mismas como "iniciadas"14. En este sentido no debe interpretarse "esotérico" como sinónimo de "secreto", ya que la teosofía tuvo mucha difusión en muchos medios de comunicación no especializados, por ser uno de sus objetivos lograr un mayor número de adeptos, pero cabe señalar que no todo el

\footnotetext{
${ }^{11}$ Casus Arzú, "El vitalismo teosófico como discurso alternativo de las élites intelectuales centroamericanas en la década de 1920 y 1930. Principales difusores: Alberto Masferrer, Carlos Wild Ospina y Porfirio Barba Jacob", REMHLAC 3, no. 1 (mayo-noviembre 2011): 3-4, https://revistas.ucr.ac.cr/index.php/rehmlac/article/view/6588/6279

${ }^{12}$ Diario Nuevo, "El viaje de Jinarajadasa, mañana celebrará sesión el comité que prepara su llegada", 6 de junio de 1938, 1.

${ }_{13}^{13}$ Diario Latino, "Jinarajadasa en Centroamérica", $1^{\circ}$ de octubre de 1938, 1 y 12.

${ }^{14}$ Valeria Aguiar Bobet, "La seducción del esoterismo: masones y teósofos en el protectorado español de Marruecos", Revista $\quad$ Melancolía 2 http://www.revistamelancolia.com/index.php/melancolia/article/view/19/23

(2017): $\quad 80$,
} 
conocimiento teosófico era público según lo determinaban sus autoridades, tal es el caso de las conferencias que hemos mencionado.

\section{Actividades de los medios escritos salvadoreños previo a la visita de Jinarajadasa al país}

Cuando Jinarajadasa estaba próximo a venir por segunda ocasión a El Salvador, en el Diario Nuevo se anunció que mediante sesión extraordinaria de la Asamblea Plenaria de las Logias Teotl y Karma, ambas con sede en la ciudad de San Salvador, se conformó un comité teosófico pro-recibimiento, el cual quedó integrado por las siguientes personas: Emilio Narváez García (presidente), Rafael Coto Romero (sindico), Juan Tavalera Crespo (pro-secretario), Emilio Fuente (tesorero) y Wenceslao Villalta (secretario) ${ }^{15}$.

Una segunda noticia sobre este mismo asunto reveló de forma contundente la íntima relación que existía entre el Presidente Martínez y las logias teosóficas mencionadas, ya que la nota periodística establecía que se habían constituido subcomités en el seno del comité referido, los cuales eran los de recaudación, gestiones, propaganda y protocolo ${ }^{16} \mathrm{y}$ que la comisión de gestiones sería la encargada de presentarse ante dicho mandatario "con el objeto de pedirle su ayuda en todos los preparativos que se estaban realizando"17.

En sesión celebrada el día sábado 21 de mayo de 1938 en casa de Juan Felipe Toruño, dicho comité dio a conocer que Jinarajadasa dictaría cinco conferencias en el país, información que había sido remitida por la logia teosófica con sede en la capital de Costa Rica $^{18}$ :

De conformidad con una comunicación llegada de la logia de San José de Costa Rica (sede de la Secretaria General de la Sección Centroamericana), la cual a su vez transcribe otra nota recibida de La Logia Central Internacional con asiento en Londres, se desprende que el filósofo hindú únicamente daría cinco conferencias en esta capital sobre temas universitarios, filosóficos y educativos ${ }^{19}$.

\footnotetext{
${ }^{15}$ Diario Nuevo, "Viene Jinarajadasa", 19 de mayo de 1938, 1.

${ }^{16}$ Diario Nuevo, "En agosto llegará el filósofo Jinarajadasa", 12 de julio de 1938, 1-2. Las sub-comisiones quedaron conformadas de la siguiente manera: Recaudación: José Trabanino (hijo), Roberto H. Banderas, Salvador Sagastizado, Salvador Brizuela, Carlos Gil, Alicia Soriano y Ofelia Montalvo; Gestiones: Andrés Soriano, Melecio Mejía Alvarado, Hugo Rinker y Rafael Coto Romero; Propaganda: Gonzalo Moreira, César Ojeda Barrios, Guillermo Argueta Bernal, Antonio Monterrosa, Zoila de Cañas, Ernestina de Chavarría, Alicia Soriano, Rafael Salinas y Rafael Coto Romero y Protocolo: Julio Enrique Ávila, Andrés Soriano, Juan Tavalera Crespo, Manuel Basilio Escobar, Federico Rinker, Roberto Agspurg, entre otros. Esta última sería la encargada de atender a Jinarajadasa.

${ }^{17}$ Diario Nuevo, "El viaje de Jinarajadasa, mañana celebrará sesión el comité que prepara su llegada", 6 de junio de 1938, 1.

${ }_{18}$ Diario Nuevo, "Cinco conferencias dará Jinarajadasa”, 21 de mayo de 1938, 1.

${ }^{19}$ Diario Nuevo, "Cinco conferencias dará Jinarajadasa", 1.
} 
Los miembros de las cuatro comisiones especiales formadas tomaron posesión de sus respectivos cargos el día 12 de agosto de 1938 y se proyectó una sesión de carácter extraordinario que se celebró el día 19 de agosto de 1938 cuyo programa fue el siguiente: $1^{\circ}$ apertura de la sesión extraordinaria presidida por los presidentes de las logias, $2^{\circ}$ conferencia doctrinaria sobre el tema "la fraternidad" por el miembro Juan Salvador Brizuela, $3^{\circ}$ lectura de la nómina de los miembros que constituían las cuatro comisiones nombradas, $4^{\circ}$ toma de protesta de los miembros nombrados por las logias, $5^{\circ}$ entrega de diplomas a los nuevos miembros de la logia Teotl expedidos por la Secretaria General y $6^{\mathbf{0}}$ discurso de clausura por el Presidente de la Logia Teotl ${ }^{20}$.

Las logias Teotl y Karma en otra sesión extraordinaria realizada en San Salvador el día miércoles 7 de septiembre de 1938 tomaron importantes resoluciones referentes a la recepción de Jinarajadasa en el país: $1^{\circ}$ se dispuso que la entrega de credenciales se hiciera por la comisión de recaudación, $2^{\circ}$ se nombró una comisión que se encargaría de gestionar ante las autoridades superiores mayores facilidades para su entrada en el país y todo lo relacionado con su alojamiento y $3^{\circ}$ se acordó hacer una activa propaganda en todos los periódicos del país, sobre todo, lo referido a la difusión de su pensamiento ${ }^{21}$.

Como preludio a la visita de Jinarajadasa a El Salvador, el Diario Nuevo publicó el artículo "El objeto de la vida" el cual fue extraído de una recopilación en inglés por Eduardo Altamirano Pavón, en el cual se elogiaba a los fundadores de las fílosofías orientales, por haber concebido ideas tan profundas como las de la "inmensidad". En el mismo, aparece también la creencia en el panteísmo cuando este establece que todas las formas y todas las existencias formaban parte de un gran "Ser Absoluto" y que en la medida que se separaban de él, se convertían en sombras ${ }^{22}$.

Nuevamente se establece de forma sólida la relación entre redes teosóficas, Diario Nuevo y el presidente Martínez cuando Altamirano ve con beneplácito el hecho de que este medio periodístico publique estos estudios teosóficos, no sólo en honor a Jinarajadasa, sino como literalmente dice el artículo como: "un obsequio de humilde valor para personas serias y estudiosas, entre las que podemos encontrar en primera línea al primer Magistrado de la Nación",23.

Este artículo no sólo tenía una gran trascendencia a nivel teosófico sino que a nivel de la filosofía en general, ya que Altamirano insinúo, sin entrar en muchos detalles de que Grecia había tomado de oriente todos los sistemas filosóficos que se desarrollaron en las

\footnotetext{
${ }^{20}$ Diario Nuevo, "Sesión de la logia Teotl", 18 de agosto de 1938, 1 y 5.

${ }^{21}$ Diario Nuevo, "Preparativos de los teósofos para recibir al filósofo Jinarajadasa", 8 de septiembre de 1938, 1 .

${ }^{22}$ Diario Nuevo, "Filosofía: el objeto de la vida", 20 de julio de 1938, 1 y 7.

${ }^{23}$ Diario Nuevo, "Filosofía: el objeto de la vida", 1 y 7 . Altamirano ve con gran admiración esta conferencia: "Es un estudio que va viviendo más de cuarenta siglos; y es por eso sin la menor duda, que los filósofos que han precedido a esos milenios, no son más que un mínimo reflejo de aquella vasta creación de la verdadera filosofía oriental".
} 
colonias del Asia menor, Atenas y la región meridional de Italia, que constituyen los ejes de la filosofía occidental; aquí empieza a dilucidarse también una oposición al materialismo y a los procesos modernizadores que se consideraban los responsables de la grave incultura del momento; ya que hizo una crítica severa a la especulación ilimitada del mercantilismo que había traído como consecuencia una degeneración moral y espiritual, ante la cual los teósofos propusieron virtudes como: la bondad, el amor y la justicia ${ }^{24}$.

En El Diario de hoy se publicó, por ejemplo, el artículo: "La Fraternidad de todo cuanto vive", en el que Jinarajadasa habló de la diferencia entre el carácter filantrópico de los teósofos y el de los cristianos, concluyendo que no había ninguna, ya que ambos tenían el mismo espíritu idealista de servicio hacia el pobre y el enfermo y que nadie lo había expresado mejor que el apóstol Santiago cuando dijo: "Toda dádiva excelente y todo don perfecto es de lo alto, y desciende del padre de las luces, en el cual no hay mudanza ni sombra de variación" $(1,17)^{25}$.

Para Jinarajadasa, todas las organizaciones espiritualistas y religiones tenían diferentes visiones de una misma realidad última a la que podía llamarse Dios o como Platón que la llamó: "lo bueno, lo bello y lo verdadero". Todas compartían el mismo idealismo. La única diferencia, era que los teósofos, según él, veían con más claridad el problema de la redención humana y estaban más atentos a darle solución, efectivamente, como lo expresó Jinarajadasa, la teosofía aportó muy poco en relación a lo que ya había sido enseñado por los filósofos orientales y occidentales hasta ese momento. Enseñanzas de las cuales nada más formuló un sincretismo ${ }^{26}$ :

Estudiad las grandes religiones, comprended lo que Platón ha dicho, y entre los pensadores modernos, entended el pensamiento de Carlyle sobre el idealismo en el trabajo, y de Rúskin sobre la belleza y la ética, y descubriréis así la Teosofía por vosotros mismos. Pero esto os llevará muchos años. En cambio estudiando unos pocos tratados de Teosofía, podréis obtened una amplia visión sobre el problema concerniente al hombre y a su evolución ${ }^{27}$.

Pero, ¿cuál era el idealismo de Tomas Carlyle en el trabajo? Carlyle creía que el hombre había sido hecho para la acción, es decir, para trabajar. Para el filósofo escocés, el pensamiento era la imagen de la acción, sin acción la filosofía sólo era apariencia de religión y de poesía. Según él, el hombre debía bastarse a sí mismo y debía enfrentar sus sufrimientos y dolores a través de la lucha y el trabajo. El hombre sólo llegaba a ser tal cuando hacía algo, es por eso que Carlyle pensaba que la mayor injusticia en el mundo era cuando un hombre tenía la voluntad de trabajar, pero no hallaba trabajo. Carlyle admiraba

\footnotetext{
${ }^{24}$ Diario Nuevo, "Filosofía: el objeto de la vida", 1 y 7.

${ }^{25}$ Jinarajadasa, "La fraternidad de todo cuanto vive", El Diario de hoy, 10 de septiembre de 1938, 6.

${ }^{26}$ Jinarajadasa, "La fraternidad de todo cuanto vive", 6.

${ }^{27}$ Jinarajadasa, "La fraternidad de todo cuanto vive", 6.
} 
especialmente dos tipos de trabajadores: al agricultor y al intelectual, ya que uno daba el pan de la vida y el otro, el pan del espíritu ${ }^{28}$.

Para Carlyle, el mayor éxito del hombre era la obra cumplida, creía que al trabajar este se ponía de acuerdo con la naturaleza para lograr su propio progreso y el de su patrono, por lo que tenía que tener un salario justo. Para Carlyle, había que desarrollar en el hombre el amor al trabajo. El no-hombre era el ocioso, es por eso que había que educar a los niños con ciertos valores como la perseverancia, la obediencia, la humildad y la disposición al perfeccionamiento. Trabajar era la única forma legítima de obtener el bienestar y es por eso que dijo: "El trabajo es vida"29.

Ahora bien ¿Cuál era la idea que John Rúskin tenía sobre la belleza? y ¿Cuál era su ética? Para Rúskin, la idea de la belleza, tenía que tener por base el gozo y el amor hacia el objeto bello, ya que este acercaba a la percepción bondadosa de una Inteligencia Superior, a la cual había que venerar. Ninguna idea u objeto podía ser bello si no se percibía con amor, no se trataba sólo de apreciar la forma sino también el contenido, la operación estética no debía ser meramente intelectual o discursiva sino emocional. Para Rúskin, el hombre tenía nublaba la inteligencia por no hacer uso de las emociones y los sentimientos, los cuales debían ser puros y no mezquinos, -la belleza- en este sentido, podía encontrase en la obra de $\operatorname{Dios}^{30}$.

Desde el punto de vista ético, Rúskin creía que la felicidad no debía buscarse en los placeres, en la ropa, en la fama o en el dinero, los cuales eran puras frivolidades, es decir, se oponía al hedonismo vulgar. En cambio para lograr la felicidad, el hombre debía disfrutar la naturaleza, leer, pensar, amar y orar, o sea, ponerse en contacto con Dios y con su obra. Para Rúskin, no se debía de enarbolar la lucha de clases, ya que creía que todas las clases se debían mutuo vasallaje. La división del trabajo en vez de ser conflictiva, debía ser cooperativa. Según él, había que orientar el trabajo al servicio de la comunidad y no aprovecharse del trabajador. Se necesitaban trabajos y salarios dignos y la producción debía ser más justamente distribuida de acuerdo a las circunstancias. Rúskin al igual que Carlyle le daba un valor fundamental al trabajo y aunque no estaba en contra del progreso, creía que había que dominar la avaricia ${ }^{31}$.

\footnotetext{
${ }^{28}$ Tomas Carlyle, ;Trabaja y confía!, normas y consejos para la orientación de la vida (Barcelona: Editorial Ossó, 1930), 193-198.

${ }^{29}$ Carlyle, ;Trabaja y confia!, 199-211.

${ }^{30}$ John Rúskin, El hombre y la naturaleza (Madrid: Editorial Espasa-Calpe, 1933), 179-182.

${ }^{31}$ Rúskin, El hombre y la naturaleza, 155-210.
} 


\section{Imagen 1}

Artículo de prensa: Lo que debemos pedir

\section{LO QUE DEBEMOS PEDIR}

Por C. JINARAJADASA

Todo cuanto debieras pedir de la vida en relación con el trabajo que ejecutas, es el que te sea permitido ir siempre adelante, siempre creando más trabajo, ejecutando más trabajo. Si nunca sueñas en recompensa alguna, bien asi de los hombres como de Dios, entonces has dado con tu trabajo, y ese es el primer paso hacia el descubrimiento de lo espiritual. Cuando hayas descubierto tu trabajo $y$, en una forma misteriosa e intuitiva, que él es parte de un trabajo más extenso aún, entonces habrás de comprender que se te necesita en tu trabajo y que eres parte del Gran Plan, que tu trabajo es semejante en mucho a la piedra de un pedestal, a la de una columna o a la de un arco, que grande o pequeña alli se le necesita. En ese trabajo has de hallar entonces satisfacción cumplida; has de descubrir que en eierto modo tal parece que existe un gran edificio en construcción y que el Arquitecto te pide traer una piedra, tu oferta, la eual El desea, $y \sin$ la cual no podrá terminarlo.

Pero no es suficiente el trabajar. Eso no constituye la verdadera conquista del espiritu. La verdadera conquista del espiritu co- mienza cuando se crea perfección por medio del trabajo que se hace, cuando se le imprime auto-marca de perfección, cualquiera que sea la obra que se ejecute. La verdadera liberación del espiritu ha de venir cuando actualices la perfección, la perfección que se halla latente en tí y cuando pulses tu propia nota, tus propias cualidades latentes de belleza y de servicio en la obra que ejecuten tus manos o inspire tu corazón. Tal es el distintivo final del espiritu.

\section{Publicaciones Recibidas}

REVISTA "AḢORA"

A nuestra mesa de redacción ha llegado el No 44 de la Revista "Ahora", correspondiente a marzo actual y que dirige en esta capital don Alfredo Ruiz C. El número que tenemos a la vista es realmente interesante. Tiene un selecto material gráfico, motivos de actualidad, $y$ lectura amena e interesante, asi como muchas fotografias de personajes sociales intelectuales del pais $y$ extranjeros; muchas gráficas de los festejos universitarios y de los festejos de carnaval efectuados reciente-

Después de la visita de Jinarajadasa a El Salvador en 1938 el suplemento La República seguía publicando pequeños fragmentos de su pensamiento así como algunos de sus ensayos completos. En este fragmento, específicamente, Jinarajadasa explicó cómo el trabajo perfeccionada al hombre a través del sacrifico y la recompensa. Ahora bien, desde un punto de vista más espiritual explicó que todas las personas tenían un trabajo que cumplir como parte del Plan de un Gran Arquitecto Superior.

Fuente: Carlos Jinarajadasa, “Lo que debemos pedir”, Diario Oficial, Suplemento La República, 19 de marzo de 1941,3 .

Ahora bien, siempre en colaboración con el comité pro-recepción de Jinarajadasa en El Salvador, El Diario de hoy también publicó el artículo "Mis gurús de Oriente y Occidente", en el cual el hindú expresaba que el mejor medio para conversar con los autores que lo inspiraban era leer sus libros, los cuales constantemente consultaba para tener claras sus ideas. Sus influencias, -según el mismo afirmaba- eran autores desconocidos como los "Upanishadas" y escritores como Dante a quien consideraba su mayor influencia literaria. Dante armonizaba con las concepciones teosóficas, ya que la 
Divina Comedia tenía un fuerte influjo de neoplatonismo ${ }^{32}$. Jinarajadasa también afirmó que le gustaba leer a Homero debido a su forma griega de ver la vida ${ }^{33}$.

Más que en un sentido intelectual, en un sentido artístico, sostenía que su segunda mayor influencia era Richard Wagner a quien se le conocía principalmente por sus dramas musicales, los cuales consideraba bien podrían ser adaptados a las obras de Esquilo. Otros autores que le influenciaban, según él, eran: Beethoven, Shakespeare y Platón, último a quien percibía como el arquetipo de hombre y a quien consideraba como la clave para entender todo lo dicho y pensado hasta ese momento. A nuestro juicio, es normal que Jinarajadasa se haya sentido influenciado por músicos, ya que otra metáfora para entender el Uno ontológico es que la esencia de todo es música. Los seres del universo forman un coro de cantantes o danzantes que tienen su vista puesta en el Uno ${ }^{34}$. Al final, venía Rúskin con su evangelio humanitario ${ }^{35}$ :

Por muchos caminos, especialmente en la economía política, marchamos en la oscuridad porque no hemos querido comprender a Rúskin. Rúskin, Dante, Platón y Wagner son mis gurús de Occidente y es por eso que digo a cada uno: Tasmai Sri Gurave namach!! (Sánscrito que quiere decir "es por eso que adoro a mi santo instructor" $" 36$.

Una vez hecha la propaganda en los periódicos, la invitación general para asistir a las conferencias de Jinarajadasa fue publicada en el Diario Nuevo el día jueves 20 de octubre de 1938. En la misma, el comité organizador invitó en nombre de las logias teosóficas, a la ciudadanía para que asistiera a dicho ciclo, que se impartiría en San Salvador en los lugares, fechas y en el orden que se detallaba conforme a un programa adjunto $^{37}$.

\footnotetext{
${ }^{32}$ Pablo García Castillo, Plotino (204/5)-270), (Madrid, España Ediciones del Orto, $\left.1^{\text {a Ed., }} 2001\right), 66$.

${ }^{33}$ Carlos Jinarajadasa, "Mis gurús de Occidente y Oriente", El Diario de hoy, 21 de septiembre de 1938, 9-10.

${ }^{34}$ Castillo, Plotino (204/5)-270, 45.

${ }^{35}$ Carlos Jinarajadasa, "Mis gurús de Occidente y Oriente”, El Diario de hoy, 21 de septiembre de 1938, 9-10.

${ }^{36}$ Jinarajadasa, "Mis gurús de Occidente y Oriente", 9-10.

${ }^{37}$ Diario Nuevo, "Programa de las conferencias del Dr. Jinarajadasa", 20 de octubre de 1938, 5.
} 


\section{Imagen 2}

Artículo de prensa: Jinarajadasa en Centro América

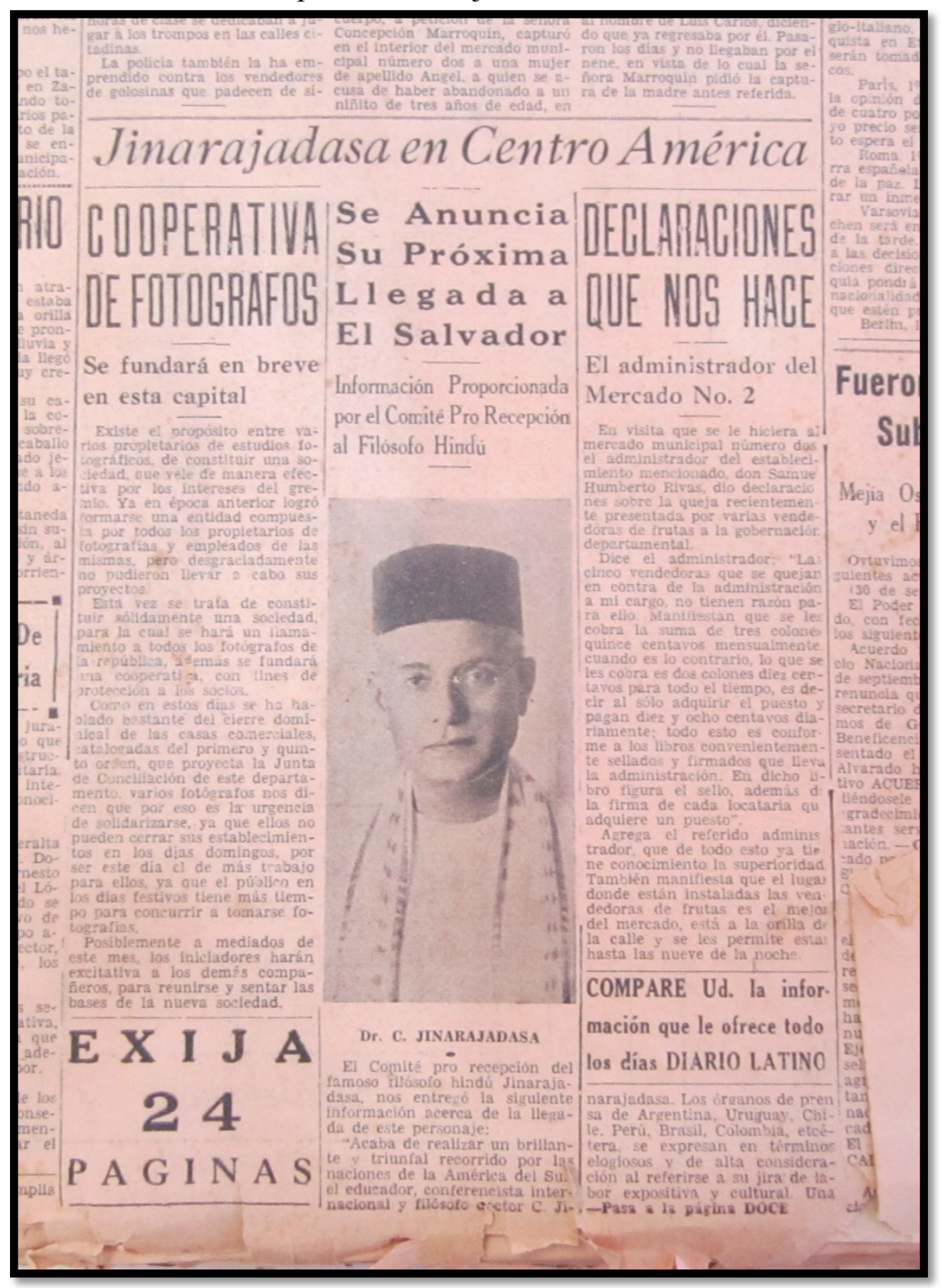

Fuente: "Jinarajadasa en Centroamérica", Diario Latino, 1 de octubre de 1938, 1.

Las conferencias de Jinarajadasa fueron radiotransmitidas a control remoto por medio de las estaciones nacionales "Y.S.S" (Alma Cuscatleca) y "Y.S.D" en onda corta y larga ${ }^{38}$ Esto último es de vital importancia ya que comprueba nuevamente la relación entre

\footnotetext{
${ }^{38}$ El Cronista, "El sabio Jinarajadasa: palpitaciones de la república de El Salvador”, 26 de octubre de 1938, 1.
} 
el Estado, la sociedad salvadoreña y las logias teosóficas en cuanto a la implementación de un proyecto de nación teosófico al utilizarse medios de comunicación gubernamentales para difundir doctrinas teosóficas en el país.

Otra forma de vinculación entre el proyecto de nación teosófica de Martínez y las logias teosóficas, fue la publicación en medios impresos (en varias entregas) de todas estas conferencias, tal fue el caso del suplemento del Diario Oficial, La República, que publicó todas a excepción de las ya señaladas e, incluso, otras que no aparecían programadas en el ciclo de conferencias del Comité, pero que eran estudios de gran relevancia. El Diario Nuevo (periódico semioficial) también participó con el Estado en la difusión de dichas doctrinas.

El Diario de hoy confirmó que la llegada de Jinarajadasa a El Salvador fue el lunes 24 de octubre de 1938 a través de la aerolínea de la Panamerican Airways S. Fue recibido en el campo de Ilopango y lo primero que se anunció es que dictaría una conferencia el miércoles 26 de octubre a las 7:30 p.m. en el Templo Masónico "Gran Logia Cuscatlán", ${ }^{39}$ pero aparentemente la disertación no se realizó, pues, Jinarajadasa no llegó el día señalado a causa de una tempestad que se desató y que le impidió salir de Tegucigalpa ${ }^{40}$. Ahora bien, las demás conferencias se realizaron en el orden previamente establecido ${ }^{41}$.

Durante la estadía de Jinarajadasa en el país, el periódico La Prensa publicó un artículo $^{42}$ referente a lo que eran los tres puntos esenciales de la "liberación" del individuo para él, los cuales eran: el dolor, la paz y la alegría. Jinarajadasa expresó que el que se liberaba se convertía en Uno con el todo. Este Uno estaba más allá de lo alto y de lo bajo, del bien y del mal, pero al mismo tiempo, todo se encontraba en él. Este Uno o Dios no podía separarse de un segundo elemento que era la "vida" a la cual podía llevar distintos mensajes, un primer mensaje era el del dolor que eran las desilusiones, los fracasos, la muerte, el pecado y todas aquellas cosas negativas que hacían que el segundo girara la vista al Uno. Jinarajadasa explicó que el dolor en esta vida terrenal liberaba, porque cumplía con una función purificadora y fortalecedora ${ }^{43}$ :

Cuando el dolor de un hombre es tan grande y lo castiga tan severamente, que nada de su yo le ha quedado para alimentar ningún sentimiento de posesión o de orgullo,

\footnotetext{
${ }^{39}$ Diario Nuevo, "La llegada de un sabio filósofo", 22 de octubre de 1938, 1 y 7.

${ }^{40}$ En este sentido el Suplemento del Diario Oficial La República en un artículo publicado el día 21 de octubre de 1938 establece que el definitivo arribo de Jinarajadasa al país fue el día lunes 24 de octubre de 1938, explicando que con ansiedad había sido esperado el domingo pasado confirmando la versión del Diario Nuevo respecto a que no le fue posible salir de Honduras debido a las condiciones meteorológicas y que debido a eso se suspendía su primera conferencia a realizarse en el instituto nacional "General Francisco Menéndez" denominada "Los niños agentes de Dios" pero que las demás conferencias se celebrarían en las fechas señaladas.

${ }^{41}$ Diario de Hoy, "Hasta ayer pudo arribar el Dr. Jinarajadasa", 25 de octubre de 1938, 3.

${ }^{42}$ La Prensa, "De las enseñanzas que da en sus conferencias el Dr. Jinarajadasa", 24 de octubre de $1938,3$.

${ }^{43}$ La Prensa, "De las enseñanzas que da en sus conferencias el Dr. Jinarajadasa", 3.
} 
entonces él encuentra una extraña cualidad en su dolor que lo hace fuerte para soportar hasta el fin, que no necesita de ningún dios que lo conforte. El dolor provoca una visión de meta en las almas ${ }^{44}$.

Por otro lado, la voluntad del "todo eterno" era la paz, paz, que se rompía ante los deseos y desesperaciones humanas, pero que podía ser dada de manera temporal por el Uno (Dios), mediante un éxtasis, un rapto o una ofrenda, teniendo las almas pequeños vislumbres de la meta final que algún día alcanzarían, que era la definitiva paz eterna de unirse de nuevo con el Uno, aunque Jinarajadasa expresó que el Uno siempre acompañaba a las almas ante las adversidades de la vida y que este era un segundo momento de liberación. El tercer momento venía con la alegría del renacimiento, idea que liberaba de las formas, pero que también podía ser alcanzada imperfectamente mediante la música, el arte, el amor o en la santidad ${ }^{45}$.

A la primera vía a la cual alude Jinarajadasa, o sea, el éxtasis, el platonista medio Máximo de Tiro, la describió como "un vislumbramiento transitorio y feliz de esa belleza inefable que ningún ojo ha visto ni poeta alguno podrá jamás cantar" ${ }^{\text {"46 }}$. Al analizarse todas estas ideas de Jinarajadasa puede observarse que hay un lenguaje que es muy alegórico y el cual aparte de la idea de la reencarnación, se asemeja mucho a los dogmas cristianos, por tener un mismo origen común: el neoplatonismo. Ahora bien, por la extensión de las conferencias que Jinarajadasa dictó en El Salvador, a continuación se tratará de rescatar la esencia de las mismas, las cuales fueron publicadas por el comité pro-Jinarajadasa en los periódicos de circulación nacional y en un opúsculo. En dichas ponencias, Jinarajadasa se presentó con sus trajes de gran ceremonia a la usanza de la India y con insignias distintivas de su rango ${ }^{47}$.

\section{Hacia la nueva humanidad de la intuición}

Jinarajadasa dictó esta conferencia a las 9:20 p.m. en el Teatro Nacional el día 24 de octubre de 1938. Inició señalando que en las sociedades contemporáneas existía un estado pasional y una lucha desenfrenada por la conquista de los mercados a nivel mundial, lo cual provocaba una deshumanización producto de que la ciencia sólo había logrado estrechar los lazos entre las naciones desde una óptica meramente material y no espiritual ${ }^{48}$.

Posteriormente criticó a los estados totalitarios de la época, por estar impregnados de ideologías radicales como el fascismo, el comunismo y el nacionalismo, que hacían

\footnotetext{
${ }^{44}$ La Prensa, "De las enseñanzas que da en sus conferencias el Dr. Jinarajadasa", 3.

${ }^{45}$ La Prensa, "De las enseñanzas que da en sus conferencias el Dr. Jinarajadasa", 3.

${ }^{46}$ Pablo García Castillo, Plotino (204/5)-270) (Madrid: Ediciones del Orto, 2001), 21.

${ }^{47}$ El Diario de hoy, "Publicarán conferencias del Dr. Jinarajadasa", 18 de noviembre de 1938, 5.

48 Jinarajadasa, "Nueva humanidad de la intuición", Diario Oficial, Suplemento La República, 21 de diciembre de 1938, 2.
} 
imposible la fraternidad mundial. Para él, era necesario contar con hombres nuevos que pudieran contemplar los problemas desde un punto de vista diferente, ya que todos los líderes mundiales de ese momento eran de tipo antisocial. Además, definió como modelos a seguir a Cristo y Buda quienes, según él, habían establecido principios universales a través de la intuición ${ }^{49}$ :

La Sociedad de las Naciones podría hacer mucho para conducirnos a la tierra de Promisión; pero la Sociedad de Naciones tal como es hoy día, con su actual mentalidad y sus actuales representantes, no puede darnos lo que el mundo necesita. Ciertamente tiene cada nación estadistas que ofrecen sus soluciones, pero estas se contradicen unas con otras, república, fascismo, estado totalitario, comunismo, monarquía constitucional y distintos sistemas de control monetario, son los varios remedios ofrecidos. Pero ni el actual tipo de republicanismo, ni el de fascismo, ni el de comunismo, aun en sus más ideales aspectos, pueden curar nuestros males ni proporcionarnos el dichoso mundo que anhelamos ${ }^{50}$.

Después definió la intuición desde el pensamiento de filósofos occidentales reconocidos como Spinoza $^{51}$ y Bergson ${ }^{52}$, para luego ofrecer un concepto propio. Jinarajadasa creía que el hombre debía despertar su intuición por medio de la observación de la naturaleza, que era un todo orgánico y vivo, lo cual reflejaba la concepción panteísta que tenía del universo. La teosofía, entonces, debía ser el nuevo método para resolver los grandes problemas sociales:

Cuando seamos intuitivos, comprenderemos por vez primera todo el caudal de potencialidad de bondad y belleza residente en nuestro interior. Entonces no necesitaremos hablar de Dios, porque le conoceremos: no necesitaremos ir a buscarle en la Iglesia ni en el templo, porque lo habremos hallado en nuestro Corazón, en nuestra mente y en la faz de nuestros prójimos ${ }^{53}$.

\footnotetext{
${ }^{49}$ Diario Nuevo, "Una brillante conferencia dio anoche el Dr. Jinarajadasa", 25 de octubre de 1938, 1-2.

${ }^{50}$ Diario Nuevo, "Una brillante conferencia dio anoche el Dr. Jinarajadasa", 1-2.

${ }^{51}$ Jinarajadasa, "Nueva humanidad de la intuición" Diario Oficial Suplemento La República, 21 de diciembre de 1938, 3. Spinoza dice que hay 3 tipos de conocimiento: 1) el empírico; 2) el racional y 3) el intuitivo que es cuando la mente ha reunido todo el material relacionando sus partes por medio de leyes. Cuando la mente contempla los hechos ordenados dentro de un marco de unidad, entonces resplandece sobre la mente una nueva facultad de intuición.

52 Jinarajadasa, "Nueva humanidad de la intuición", 3. Bergson sostiene que la intuición está relacionada con el instinto; que es una forma sutil y dormida del instinto. Bergson sostenía que el instinto llevaba a la acción, tal como ocurre con los animales, que actúan por instinto nada más. La inteligencia humana puede a menudo superar al instinto del animal, pero el instinto es más radical porque está basado en la vida; no obra de modo mecánico, como si fuera una máquina accionada por las fuerzas de la materia, porque el instinto para Bergson es algo vivo.

53 Jinarajadasa, "Nueva humanidad de la intuición”, 3.
} 
Henri Bergson contrario a lo que pudiera pensarse, además del método de la intuición tuvo muchas otras cosas más en común con la teosofía, también criticó al positivismo, principalmente al mecanicismo y al evolucionismo de Herbert Spencer. Bergson también era neoplatónico, es decir, creía en la doctrina del Uno en multiplicidad y trató de hacer un integracionismo entre ciencia, metafísica ${ }^{54}$ y fe, incluso, terminó en una especie de misticismo filosófico y afirmó la existencia de Dios ${ }^{55}$.

Michel Barlow considera que la idea de la "nada" bergsoniana ha sido interpretada como un panteísmo inmanentista. Otra similitud sería que, Bergson también llegó a admitir la posibilidad de la inmortalidad del alma y estableció la teoría de la creación como un hecho. El padre del intuicionismo moderno, creía que la evolución simplemente había sido una continuidad de la creación. Barlow también concluye que la base de su pensamiento era el hecho místico. Bergson expresó su admiración por el judaísmo y estuvo en contra del antisemitismo, porque Bergson naturalmente era judío ${ }^{56}$. Lo paradójico del caso es que tanto Martín Heidegger ligado al Partido Nacional Socialista como Bergson son considerados hoy en día como los filósofos místicos del "ser".

Bergson criticaba a la filosofía tradicional por plantear problemas que, según él, de antemano tenía resueltos mediante el uso del lenguaje. Para él, de forma muy similar a Krishnamurti y Huxley, la verdad no debía ser reducida a esgrimir conceptos sino que a captar realidades. La base de su filosofía era que las palabras artificiales no necesariamente correspondían a la esencia de las cosas, sostenía que la filosofía había ordenado el pensamiento y que arbitrariamente lo había adecuado a la realidad, por lo que contrariamente lo que había conseguido la sabiduría occidental era deformarla o falsearla ${ }^{57}$.

Bergson estaba en contra de las matemáticas, por ejemplo, consideraba que funciones como las de sentir eran superiores a las de medir y de ahí su afición a la psicología. Para él, la física y la química tampoco podían dar la clave de la vida sino sólo la intuición que era el método de la metafísica. Bergson, en resumen, trató de contraponerse a la frialdad del cálculo y a los conceptos de la física clásica de espacio-tiempo (duración). Ahora bien, la teosofía además de interesarse por el aspecto propiamente filosófico también se interesó por lo pedagógico, aludiendo a que la intuición también tenía que ser aplicada a la enseñanza ${ }^{58}$.

\footnotetext{
${ }^{54}$ Henri Bergson, Memoria y vida, textos escogidos por Gilles Deleuze (Madrid: Alianza Editorial, S.A., 1977), 19-46.

55 Michel Barlow, El pensamiento de Henri Bergson (Ciudad de México: Fondo de Cultura Económica, 1968), 35-125.

${ }^{56}$ Barlow, El pensamiento de Henri Bergson, 126- 128.

${ }^{57}$ Bergson, Memoria y vida, 23-27.

${ }^{58}$ Bergson, Memoria y vida, 10-29.
} 


\section{Imagen 3}

Artículo de prensa: Doctrina de la intuición aplicada a la enseñanza

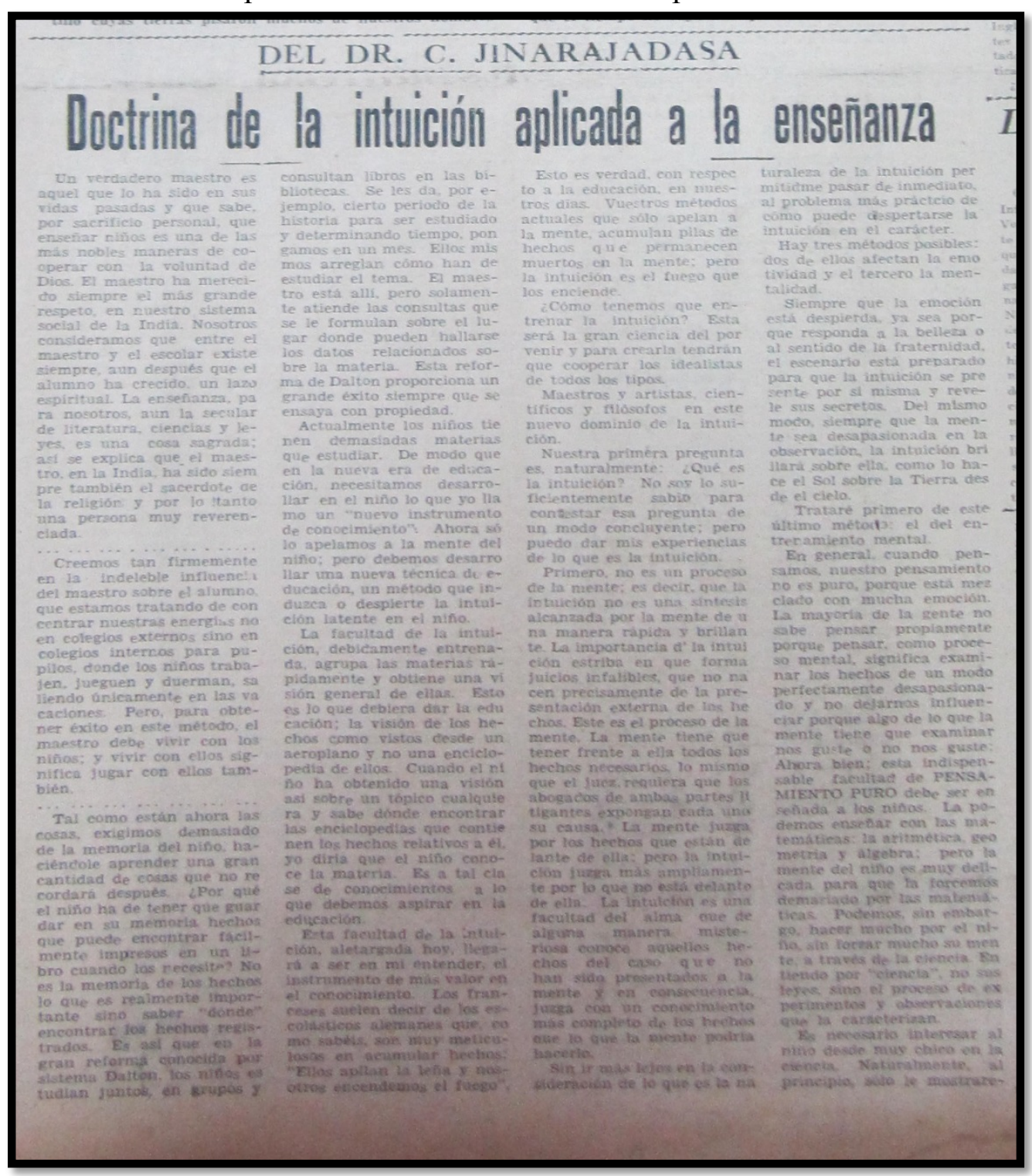

Fuente: Jinarajadasa, "Doctrina de la enseñanza aplicada a la intuición”, Diario Nuevo, 23 de septiembre de 1938,5 .

\section{La teosofía y el destino de la humanidad}

Jinarajadasa dictó esta conferencia a las 5:30 p.m. en la Sociedad de Empleados de Comercio de San Salvador el día 25 de octubre de 1938. Para él, cada individuo se encontraba sumergido en sus propios pensamientos, observando la realidad de otros pueblos como muy lejanas; estableció que las religiones también contribuían a estrechar el 
campo visual alejando a las personas del mundo. Veía a los griegos como el único pueblo que se ha vinculado a la humanidad y a su vida espiritual, ya que, por ejemplo, buscaron en el atletismo un fin tanto espiritual como material (salud y diversión) ${ }^{59}$.

Desde su perspectiva, ellos consideraban como algo trascendental el cultivo de la "política" porque era la única forma de producir al "ciudadano" sano, instruido e inclinado hacia la espiritualidad ${ }^{60}$, pudiendo hipotetizar que durante el régimen martinista también se buscó este nuevo tipo de ciudadano que se interesará por el cultivo de lo intelectual y lo especulativo, pero también por el cultivo del cuerpo, una muestra de ello podrían ser los "Juegos Olímpicos Centroamericanos" realizados en San Salvador en 1935. La visión educativa de Martínez vale decir era crear hombres de cuerpo y mente sana.

Jinarajadasa de forma similar a Hegel pensaba que todo dependía de todo como en un sistema, aunque estuviéramos ensimismados en nuestros propios asuntos estos estaban ligados con los de todo el mundo. Asimismo, pensaba que ningún país se encontraba aislado. Las barreras eran imaginarias y se empezaban a derribar, según él, cuando se sentía algún interés por la literatura, la pintura o la escultura de otros países, es decir, cuando se descubría que había una humanidad en su conjunto ${ }^{61}$.

Entonces, ante la pregunta: ¿Qué hay en el mundo? Jinarajadasa ${ }^{62}$ respondería que tanto de la ciencia como de la religión eran insuficientes, que la única respuesta integral podía ser brindada por la teosofía, en el sentido de que esta no debía ser aceptada por lo que ella decía de sí misma, sino porque ofrecía un nuevo punto de partida que debía ser examinado por cada uno. También aclaró que tal cual como en el método científico, la teosofía debía ser desechada si sus hipótesis no explicaban eficientemente la realidad, es decir, invitaba a estudiar dichas doctrinas con un sentido crítico. Ahora bien ¿Cuál era la hipótesis de la teosofía con respecto al mundo? Siempre de forma dogmática respondió que todo obedecía a un plan preconcebido en donde todo funcionaba por causalidad y no por casualidad $^{63}$.

Las migraciones, la aparición y desaparición de civilizaciones e incluso las guerras formaban parte de este plan único y era trazado por un "Dios", pero no un Dios antropomorfo que resultaba inadecuado desde esta perspectiva, sino como una inteligencia que funcionaba en toda su plenitud operando en todas partes, siendo más adecuado utilizar

\footnotetext{
59 Jinarajadasa, "La teosofía y el destino de La Humanidad”, Diario Oficial, Suplemento La República, 27 de diciembre de 1938, 2.

60 Jinarajadasa "La teosofía y el destino de La Humanidad", 2.

${ }^{61}$ Jinarajadasa "La teosofía y el destino de La Humanidad", 2.

${ }^{62}$ Casaús Arzú, "La disputa por los espacios públicos en Centroamérica de las redes unionistas y teosóficas en la década de 1920: La figura de Alberto Masferrer.", Revista Humanidades IV, no. 2, (2003): 58. Casaús establece que uno de los máximos inspiradores de Masferrer fue Carlos Jinarajadasa y que inclusive público un artículo denominado "Mi conversación íntima con Jinarajadasa", en el periódico Patria.

${ }^{63}$ Jinarajadasa, "La teosofía y el destino de la humanidad", Diario Oficial, Suplemento La República, 27 de diciembre de 1938, 2.
} 
el concepto estoico del logos que, según él, era sinónimo de "universo" o la "expresión suprema de la razón", que en el cristianismo se tradujo por "verbo": "y el verbo se hizo carne", pero, para Jinarajadasa, era más adecuado utilizar el concepto de logos porque evitaba la idea de personalidad. El objetivo de este logos era el andamiaje o armazón del mundo ${ }^{64}$.

Las pruebas que la teosofía ofrecía para comprobar esta hipótesis eran las siguientes: 1) todo antes de su existencia surgió como pensamiento en la mente del logos luego se volvió energía, materia, acción y finalmente ley, 2) el logos una vez revestido de materia inició su proceso de evolución, pero de forma predeterminada, no como prueba y error como afirma la ciencia, 3) todo cuanto existe no son meras creaciones del logos sino que constituyen el logos mismo, 4) todo el universo cambia para revelar la naturaleza del logos, 5) el $\log o s$ es fuente y origen de todo el amor, 6) El logos es un ente actuante, un escultor, 7) el logos para cumplir su misión necesita al hombre por lo que el hombre se convierte en agente de Dios y 8) el propósito del logos es que las almas humanas se conviertan en sus colaboradoras ${ }^{65}$.

Ahora bien, el $\log o$ s no obligaba a nadie a seguir su plan sino que apelaba a la intuición de las almas por medio de los instructores y para que la humanidad trabajara conjuntamente con él, pero primero se tenía que comprender su voluntad, la cual era formar una organización mundial y formar sociedades económicas entre las naciones en las cuales se compartieran la prosperidad y la miseria, es decir, la teosofía planteaba construir un mundo más solidario y unido. Para Jinarajadasa, a esto iba encaminado el destino de la humanidad $^{66}$, pero ahora que se ha visto el aspecto humanístico de la teosofía, se analizará la visión que Jinarajadasa tenía sobre el cristianismo occidental en sus dos grandes ramas: catolicismo y protestantismo.

\section{El trabajo de Cristo en el mundo de hoy}

Jinarajadasa desarrolló esta conferencia a las 9:20 p.m. en el Teatro Nacional el día 25 de octubre de 1938. Aquí sostuvo que en el mundo occidental el cristianismo ha fracasado porque es un movimiento espiritual que ha contado con más de dos mil años de expansión, y a pesar de ello, ha tenido muy pocos resultados en su misión de regenerar a la humanidad. Esto lo afirmaba debido a que las enseñanzas de Cristo poco a poco habían dejado de ser asimiladas. Jinarajadasa pensaba que cuando Cristo anduvo entre sus

\footnotetext{
${ }^{64}$ Jinarajadasa, "La teosofía y el destino de la humanidad", 2-3.

${ }^{65}$ Jinarajadasa, "La teosofía y el destino de la humanidad", 28 de diciembre de 1938, 2.

${ }^{66}$ Jinarajadasa, "La teosofía y el destino de la humanidad", 2.
} 
discípulos fue considerado como un "hermano mayor" en el que intuyeron la esencia de su idealismo $^{67}$, es decir, al igual que Masferrer creía que Cristo había sido un iniciado.

Sostenía que Pablo por su parte predicó la doctrina de la salvación tradicional, pero que agregó algo nuevo, lo cual fue que proveyó el concepto de que Cristo era un modelo al cual todo hombre estaba obligado a seguir, por tanto, San Pablo, a su juicio, fue quien introdujo el concepto de que debía existir una relación mística entre el hombre y Cristo. San Juan por su lado, reveló el aspecto cósmico de Cristo; el Cristo que se convirtió en el "verbo", "la razón divina", el logos de los estoicos, "el divino orden del universo", el Dios que geometriza y que fue hecho hombre en las tierras de Palestina: la "totalidad" del universo en un ser humano ${ }^{68}$.

El fracaso de la Iglesia y del cristianismo, por tanto, radicaba en su acercamiento a Juan y su alejamiento de Pablo, es decir, en haberse alejado de Cristo como persona, quedándose sólo con los elementos místicos, de ahí en adelante, creía se había iniciado la corrupción de la Iglesia católica que empezó a hablar en nombre de Cristo y sustituyó su cuerpo mediante los sacramentos de la eucaristía, siendo por este mismo tiempo, que introdujo a María como intercesora espiritual entre Cristo y la humanidad e incorporó la idea del sacerdote como intercesor entre Dios y el hombre. Jinarajadasa creía que el protestantismo, por el contrario, había tomado la imagen de Cristo como Dios-hombre y que en ese sentido, había tenido un poco de retorno a la persona de Cristo, ya que, en teoría, se oponía a los "intercesores",69.

Luego Jinarajadasa explicó de forma contradictoria que ese fue precisamente el error de los reformadores protestantes, ya que Dios utilizaba distintos medios para llegar a la humanidad: la Iglesia, los sacerdotes, etc., porque Dios no sólo fundó la religión ${ }^{70}$ y se apartó de ella, sino que todavía estaba guiándola (concepto del Dios masón geómetra), por lo que todas estas manifestaciones eran inspiraciones de su fundador. Jinarajadasa pensaba que la "alta crítica" por su parte, eliminó la naturaleza divina de Cristo reduciéndolo a ser un simple hombre, descartando los milagros como hechos históricos comprobables.

Ante esta postura, Jinarajadasa explicó que la divinidad siempre se había manifestado mediante un ser humano y que desde la teosofía había podido encontrar a Cristo, además que lo había estado sirviendo durante toda su vida bajo el principio establecido por San Pablo, que enseñaba que la naturaleza de lo divino se encontraba en nosotros mismos, cuestión que también fue dilucidada por el mismo Cristo cuando lo

\footnotetext{
${ }^{67}$ Jinarajadasa, "El trabajo de Cristo en el mundo de hoy", Diario Oficial, Suplemento La República, 14 de noviembre de 1938, 2.

${ }^{68}$ Jinarajadasa, "El trabajo de Cristo en el mundo de hoy", 2.

${ }_{70}^{69}$ Jinarajadasa, "El trabajo de Cristo en el mundo de hoy", 2.

${ }^{70}$ Diario Nuevo, "Plática del Señor Presidente General Martínez", 21 de octubre de 1943, 3. "Toda religión debe ser un alto espíritu religioso. La religión conduce al hombre al eslabonamiento de su ser con la divinidad, cualquiera que sea el concepto que de ella tenga. Por consiguiente las religiones, no son guerreras sino pacifistas. La guerra es destrucción y la religión vida".
} 
interrogaron si él era Dios: "yo dije: vosotros sois dioses y todos vosotros hijos del altísimo" (Salmos 82.6).

La diferencia entre Cristo y el resto de la humanidad era que este liberó su divinidad y alcanzó la perfección mediante el proceso de transubstanciación. Nosotros en menor grado debíamos imitarlo porque, Cristo, para Jinarajadasa, fue al igual que Buda, uno de los grandes seres que había encarnado para ayudar a la humanidad y que al estar en un cuerpo humano de ningún modo disminuyó su poder y divinidad ${ }^{71}$.

Para estos grandes seres, según él, no hubo divisiones de religiones o sectas, ya que todas las creencias estaban presentes en ellos, es decir, ayudaron a toda la humanidad con prescindencia de su credo, porque todos ellos provenían de un mismo principio único y divino. Las ciencias, las artes, la filosofía y los misticismos eran el resultado de la acción divina destinada a elevar a los hombres hacia Dios. La idea consistía en que cada uno en su propio ciclo evolutivo podía descubrir al Dios que aún no había despertado en él, para lo cual se contaba con la ayuda de Cristo que se encargó de organizar al mundo ${ }^{72}$.

En otras palabras, Jinarajadasa creía que la teosofía podía realizar mejor esta función que las religiones y las sectas tradicionales ya que estas sólo dividían a los hombres fruto de sus distintos criterios, y porque el principio que Cristo dejo establecido fue el de crear la fraternidad universal. Otros de estos agentes que ayudaban a este objetivo eran los Boys Scouts ${ }^{73}$ y el denominado "Movimiento de Oxford" y en esto consistía el gran experimento teosófico. ${ }^{74}$ En la siguiente conferencia se verá cómo dentro de este mismo plan teosófico providencial, el niño tenía un papel preponderante.

\section{Los niños agentes de Dios}

Jinarajadasa llevó a cabo esta conferencia a las 8:00 p.m. en la Sociedad de Empleados de Comercio de San Salvador el día 27 de octubre de 1938. Para él, en su tiempo, hubo varias tendencias de regeneración y hubo más idealistas y reformadores que en cualquier otra época de la humanidad. En todos los países del mundo, surgieron nuevos movimientos espiritualistas que trataron de abolir la pobreza, la ignorancia y anhelaron construir la democracia, es decir, en todas partes se trabajó por la reconstrucción del

\footnotetext{
${ }^{71}$ Jinarajadasa, "El trabajo de Cristo en el mundo de hoy", Diario Oficial, Suplemento La República, 14 de noviembre de 1938, 2-3.

72 Jinarajadasa, "El trabajo de Cristo en el mundo de hoy", 2-3.

${ }^{73}$ La Prensa, "Los Boys Scouts han comenzado a organizarse en la República", 16 de mayo de 1933, 1. El General Maximiliano Hernández Martínez fue presidente honorario de esta agrupación en El Salvador la cual tendría la protección del supremo Gobierno que donaría los uniformes y sería organizada bajo los auspicios del Club Rotario de procedencia Estadounidense. El objetivo era formar parte de la Gran Hermandad Internacional de Scouts.

${ }^{74}$ Jinarajadasa, "El trabajo de Cristo en el mundo de hoy”, Diario Oficial, Suplemento La República, 14-15 de noviembre de 1938, 3 .
} 
mundo. La Sociedad de las Naciones por su parte, tuvo la misión de erradicar las guerras en el globo, pero también existió otro movimiento que estuvo encaminado a lograr el desarrollo de la humanidad, el cual fue la obra "pro-niño" (quizás a través de estas ideas vale decir que el gobierno del Presidente Martínez también inició una campaña proinfancia) $)^{75}$, la cual funcionó mediante la visión de que el niño era el futuro de la nación y del Estado, idea que la teosofía tomó del padre de la pedagogía racional: Johan Heinrich Pestalozzi (1746-1827) ${ }^{76}$.

Jinarajadasa sostenía que muchos estudiosos durante el siglo XIX quisieron aplicar este sistema como programa de instrucción pública, el cual el mismo Napoleón no quiso implementar para Francia, lo cual a su juicio fue un grave error. Según él, los gobiernos tenían que volver a retomar esta iniciativa para crear una nueva revolución basada en Pestalozzi, Froebel y Montessori, quienes trataron la naturaleza "trina" del niño: física, mental y emocional, sólo que enfocándose en el desarrollo psíquico o espiritual (alma), o sea, acentuando más el aspecto místico que el material. Jinarajadasa dijo que Pestalozzi se convirtió en el máximo reformador porque vio en el niño no un problema sino una manifestación de Dios ${ }^{77}$.

Jinarajadasa pensaba que todos los enunciados pedagógicos de Pestalozzi tenían que aplicarse en las escuelas normales porque estaban fundamentados en el amor, que era el punto central de toda educación, pero además de eso, también se tenía que cambiar la mentalidad de los profesores para que estos aprendieran a despertar las facultades intrínsecas de los niños, sobre todo, su voluntad y que por ese motivo fue que Froebel (discípulo de Pestalozzi), ideó los kindergarten donde el niño se expresaba de forma espontánea $^{78}$.

\footnotetext{
${ }^{75}$ Diario Oficial, Suplemento La República, "Las ideas del General Martínez", 14 de enero de 1941, 1. "En la plática que dio recientemente el General Hernández Martínez, a excitativa de la Asociación Nacional ProInfancia (anexo del partido Pro-Patria), puso de relieve ideas substanciales acerca de la finalidad altamente meritoria que se persigue en la campaña que se ha iniciado en el territorio nacional a favor de la niñez salvadoreña. Estas ideas son acreedoras de un acucioso estudio porque ellas en si definen lo que debe ser la campaña Pro-infancia que con tanto entusiasmo llevan a cabo distinguidos elementos de nuestra sociedad, apoyados por los poderes del Estado. En uno de nuestros comentarios anteriores decíamos que la campaña Pro-infancia no se concreta únicamente a buscar los medios para que la niñez este rodeada de comodidades y bienestar físico, sino que de algo mejor como es el de crear fuerzas de defensa espiritual, fuerzas que actúen en la formación del alma de los hombres del mañana. Fuerzas que preparen a las juventudes para que tengan días mejores y puedan vivir en un mundo también mejor".

${ }^{76}$ Jinarajadasa, "Los agentes de Dios: los niños", Diario Oficial, Suplemento La República, 25 de noviembre de 1938, 2.

${ }_{77}^{71}$ Jinarajadasa, "Los agentes de Dios: los niños", 2.

${ }^{78}$ Diario Nuevo, "Plática del Señor Presidente Hernández Martínez sobre la carta del Atlántico", $1^{\circ}$ de abril de 1943, 3. "Tenemos que cambiar los sistemas educativos del mundo. En la actualidad las escuelas, desde el Kindergarten hasta la Universidad, persiguen únicamente la ilustración del individuo. Quieren prepararlo mejor por la lucha por la vida. Se le dice a cada uno: Tú debes ser superior a los otros. Esto no puede seguir así. Demos a todos la ambición pero no la ambición de conquistas materiales. Si el anhelo de obtener una mayor espiritualidad que nos haga sentirnos hermanos de todos y por lo tanto servidores de todos. Formemos a los nuevos mentores para las generaciones nuevas".
} 
Posterior a esto, manifestó que la pedagoga Montesori continuó esta tarea sólo que de forma más amplia, cuyo propósito fue la formación del carácter y conciencia del niño por medio del estímulo. La intención de la charla era demostrar que el niño tenía su propia individualidad y potencialidades, por lo que había que descubrir al niño y liberarlo. El deber de los padres y maestros consistía, pues, en proporcionar un ambiente adecuado para desarrollar la naturaleza síquica del niño, sin imponerle patrones o moldes, a su propio ritmo y ayudándole a encontrar sus intereses ${ }^{79}$.

Jinarajadasa trataba de hibridar elementos místicos y pedagógicos al establecer que Montessori llamó a los niños "pequeños mesías" que revelaban los misterios de Dios, idea que esta desarrolló en su libro El Niño, mediante tres postulados básicos: 1) los niños son encarnaciones de Dios en su diminuto cuerpo, 2) el niño encierra secretos capaces de resolver los problemas de la vida adulta tanto individuales como sociales y 3) hay que ayudar a los niños a descubrir su propio Cristo oculto. En base a estos principios, Jinarajadasa pensó que se debía reformar la educación a profundidad y es la razón del porque los teósofos trabajaron en favor del niño ${ }^{80}$.

La teosofía de este modo, propuso una nueva visión pedagógica, incluso mediante la fundación de una organización llamada "Nueva Fraternidad Teosófica de Educación" auspiciada en Inglaterra por algunos teósofos que según Jinarajadasa funcionó en algunos países de Europa y Norteamérica; dicha institución tuvo a su cargo la publicación de una revista en tres idiomas, celebró congresos en Europa, Sudáfrica y Australia y fundó algunas escuelas experimentales en base a estas ideas. Para los teósofos, el niño no era como una página en blanco (tabla rasa) sino que tenía algunas ideas innatas, por lo que había que estimular sus tendencias positivas que permanecían dormidas ${ }^{81}$.

Según los teósofos, los adultos eran los responsables de la conducta antisocial que desarrollaban los niños, no se trataba de quererlos dominar u oprimir, sino que más bien había que desarrollar su espiritualidad y sabiduría, aprovechando su papel de "intercesores" 82 entre el hombre y Dios (mundo invisible), siendo este uno de los secretos que había revelado Cristo y Krishna, cosa que los hombres aún no comprendían, los niños en este sentido, eran mensajeros del reino de la belleza, fuerza y sabiduría o, en otras

\footnotetext{
${ }^{79}$ Jinarajadasa, "Los agentes de Dios: los niños”, Diario Oficial, Suplemento La República, 25 de noviembre de 1938, 2-3.

${ }^{80}$ Jinarajadasa, "Los agentes de Dios: los niños", 2-3.

${ }^{81}$ Jinarajadasa, "Los agentes de Dios: los niños", 26 de noviembre de 1938, 2.

${ }^{82}$ Diario Oficial, Suplemento La República, "El General Martínez responde cuatro preguntas de interés.”, 4 de febrero de 1943, 4. "Como un canal somos los hombres. Por nosotros corre la "Divina Sabiduría" para bien de los demás. Dios quiere que por medio de estos canales pase la virtud que destruya el mal que nosotros hemos creado.
} 
palabras, "agentes de Dios" ${ }^{\$ 3}$. Ahora que se ha visto la importancia del niño para la teosofía, se profundizara en cómo esta adoptó la teoría de la reencarnación ${ }^{84}$.

\section{El crecimiento del alma a través del proceso de reencarnación}

En este artículo, Jinarajadasa desarrolló la idea de que las almas tienen sucesivas existencias y que dependiendo de su karma acumulado son recompensadas reencarnando de distintas maneras en la vida presente. Para ilustrar lo dicho, Jinarajadasa puso el ejemplo de dos niños, uno que nació sano y protegido por su familia y otro que nació ciego, pobre y desamparado. Este último, según el teósofo nació así por haber perdido en sus vidas anteriores muchas oportunidades de perfeccionamiento ${ }^{85}$.

Esta opinión se oponía a la de los ateos, para quienes esto no era más que fruto de la casualidad, pero Jinarajadasa creía que esta respuesta no era suficiente para resolver el problema. Por otro lado, también cuestionaba la respuesta de los teístas al reflexionar sobre el dilema, ya que sí era verdad que existía un Dios que regía todas las cosas, perfecto y que era todo amor, entonces por qué creaba un alma y la ponía en un cuerpo ciego, luego creaba otra y la ponía en un cuerpo sano, acaso ¿Sería un Dios injusto? ¿Preguntar sobre estas cosas constituía una blasfemia por intentar entender los misterios de Dios? Jinarajadasa contestaría que de ningún modo Dios le había vedado al hombre conocer sus leyes de la naturaleza, que por el contrario, era uno de los objetivos de la Sociedad Teosófica ${ }^{86}$.

Para Jinarajadasa, la inteligencia humana al conocer estos misterios (leyes) conocía y amaba a Dios de una forma más adecuada. Las tres teorías tradicionales para explicar el fenómeno al que se ha hecho referencia son: 1) Dios en su justicia le dará al hombre ciego más oportunidades que en vida no tuvo, corrigiendo y arreglando mediante una compensación la injusticia original, para muchos esto es inaceptable porque menguaría la bondad de Dios, 2) la teoría de la preexistencia, en la que Dios creó el alma, no en el momento de la concepción o nacimiento sino antes, de modo que el alma ya vivió en los reinos invisibles haciendo cosas buenas y malas, posteriormente fue enviada a vivir en el cuerpo de un bebé según su comportamiento ${ }^{87}$.

Esta fue la teoría que aceptaron los judíos en el tiempo que vivió Cristo, para demostrarlo Jinarajadasa citó un pasaje de la Biblia: "y al pasar Jesús, vio un hombre ciego de nacimiento y le preguntaron sus discípulos: maestro ¿Quién pecó, este o sus padres, para haber nacido ciego? (Jn. 9, 1.41). Además, de revelar la creencia en la preexistencia del

\footnotetext{
${ }^{83}$ Jinarajadasa, "Los agentes de Dios: los niños", Diario Oficial, Suplemento La República, 26 de noviembre de $1938,3$.

${ }^{84}$ García Castillo, Plotino (204/5)-270), 26.

${ }^{85}$ Jinarajadasa, "El Crecimiento del alma a través del Proceso de Reencarnación", Diario Oficial, Suplemento La República, 9 de diciembre de 1938, 2-3.

${ }^{86}$ Jinarajadasa, "El Crecimiento del alma a través del Proceso de Reencarnación", 2-3.

${ }^{87}$ Jinarajadasa, "El Crecimiento del alma a través del Proceso de Reencarnación", 2-3.
} 
alma, también muestra la creencia judía de la transmisión del pecado hasta la tercera y cuarta generación y 3) la teoría de la reencarnación ${ }^{88}$, la que expresaría que un bebé ya vivió muchas veces en otros lugares de la tierra en otras vidas ${ }^{89}$.

Jinarajadasa en base a esta última hipótesis dijo que el alma pasaba por el purgatorio, luego renacía siempre hombre y nunca en el cuerpo de un animal, teoría que no era parte de la teosofía, por ser considerada una "superstición" en el sentido de que un animal no tiene uso de razón, por tanto, un alma pecadora en ese estado no podía comprender su sufrimiento para modificar posteriormente su carácter. El credo de la reencarnación, según el teósofo, era arquetípica en todas las civilizaciones, aparece en el libro de los druidas De la guerra de las Galias, en el que están presentes las nociones de inmortalidad y transmigración de las almas; también fue profesada por los aborígenes de Australia, Canadá y África quienes la establecieron como ley de la naturaleza al igual que Pitágoras y Platón. Virgilio también la proclamó en el libro sexto de La Eneida, de modo que Jinarajadasa demostró que esta idea era muy antigua y aparecía en múltiples culturas ${ }^{90}$.

Para los judíos, solo los profetas como Elías reencarnaban, por ejemplo, especularon si este había reencarnado en Juan el bautista o hasta en el mismo Jesús, así la concepción de la reencarnación sólo estuvo limitada para los mensajeros de Dios. En el hinduismo y el budismo la reencarnación fue aceptada como una ley de la existencia ${ }^{91}$, ambas sostenían que el alma tenía que desarrollarse y purificarse hasta alcanzar la máxima bondad, en el hinduismo en la unión inseparable con Dios y en el budismo mediante la liberación llamada "nirvana", en donde el alma vivía sin limitaciones. Esta purificación tenía que realizarse mediante un proceso gradual, pasar por varias vidas para llegar a ser completa y se encontraba en íntima relación con la ley del karma, palabra que proviene del sánscrito que

${ }^{88}$ A. G. Tavel, "Teosofía”, El Cronista, 15 de octubre de 1938, 1 y 8. "Según estas doctrinas el alma ha existido siempre y no puede morir, cosa que no se puede probar ni lógica, ni científicamente, y racionalmente es una teoría más. Para ella nacer es tomar un cuerpo físico perecedero, morir es desprenderse de dicho cuerpo y según esto el alma tiene que reencarnarse para expiar sus culpas en otro cuerpo, del cual se posesiona hasta que haya logrado libertarse en la rueda de nacimientos y muertes, entonces retorna a su principio que según la misma teoría es la divinidad".

89 Jinarajadasa, "El crecimiento del alma a través del proceso de reencarnación", Diario Oficial, Suplemento La República, 9 de diciembre de 1938, 2-3.

90 A. G. Tavel, "Teosofía”, El Cronista, 15 de octubre de 1938, 1 y 8. "La transmigración ascendente de las almas es una simple hipótesis cuya demostración "a priori" parece casi imposible aún a los mismos teorizantes. Esta hipótesis ha sido sostenida por lo más bellos genios de todos los tiempos Pitágoras, Sócrates, Platón, etc. razón por la cual nos parece que una idea que se presenta en el mundo filosófico con semejantes enseñadores podría luchar en contra del positivismo moderno, más debemos confesar que es un problema obscuro, aunque respetamos y profesamos veneración por los grandes hombres que acabamos de citar, más debemos decir a la verdad que no nos inclinamos jamás delante de su autoridad hasta no haber tenido conocimiento del -cómo y del por qué- de estas transmigraciones.

91 Jinarajadasa, "La actitud teosófica ante la pérdida de un ser amado", Diario Latino, 3 de octubre de $1938,3$. "Cuando llega el fenómeno que llamamos muerte ha dado fin a sus labores el plano físico en esta encarnación y como el niño que aprobado, en sus exámenes, pasa un grado de la escuela a otro superior, así pasa la personalidad a una superior etapa de conciencia (...) es sin embargo para el desencarnado, el comienzo de otra etapa de su desarrollo". 
significa "acción" que constituye la tercer ley física de Newton que puede sintetizarse en la expresión: "así como es la acción, así es la reacción".

Entonces, según Jinarajadasa, cuando se nace ya se viene cargado de un pasado donde hemos pensado y actuado correcta e incorrectamente, que es lo que determina nuestra aparición en este mundo, por lo tanto, Dios no castiga sino que simplemente, ha dejado la ley de acción y reacción, la cual al quebrantarse produce sus efectos ${ }^{93}$.

En esta dirección, de ningún modo habría que ver a la teoría de la reencarnación como algo descabellado, Juan Antonio Estrada S.J. cree que detrás de esta creencia hay un fundamento órfico-pitagórico mediante el cual se establece que el alma es prisionera del cuerpo de manera temporal, pero que en el fondo, trata de enfrentarse al problema del mal ético mediante la acumulación de méritos ante la divinidad. El problema ético se encuentra determinado por la situación del alma en el mundo físico y la doctrina de la transmigración de las almas es la mejor respuesta ante el mal humano. El filósofo español considera que la lucha contra el mal viene dada por la superación de lo material a través de lo espiritual, es decir, Dios tiene un plan pedagógico en donde el alma desciende a un estado corporalanimal debido a una culpa, pero que una vez aprendida la lección se vuelve a elevar al campo de lo espiritual $^{94}$ :

El sistema platónico ofrece un marco de comprensión muy sugerente, cuyo influjo se mantiene hasta nuestros días. Al explicar el mal como una caída y aludir al trasfondo de las reencarnaciones se ofrece una explicación válida y universal del sufrimiento humano. En última instancia la teoría de la caída unida a la de la reencarnación juega en la comprensión griega un papel parecido al del pecado original en la tradición dogmática postagustiniana. La caída y el comportamiento en las anteriores vidas permiten explicar de forma coherente los sufrimientos de la vida presente $^{95}$.

Habría que señalar que estas concepciones fueron las que predominaron desde Platón hasta Plotino en un periodo de seis siglos ${ }^{96}$, es decir, la teosofía se encuentra profundamente influenciada por los diferentes autores y períodos de la tradición platónica, tal y como puede reafirmarse en el siguiente estudio.

\footnotetext{
92 Jinarajadasa "El crecimiento del alma a través del Proceso de Reencarnación”, Diario Oficial, Suplemento La República, 9 de diciembre de 1938, 2-3.

93 Jinarajadasa "El crecimiento del alma a través del Proceso de Reencarnación”, 2-3.

94 Juan Antonio Estrada, La imposible teodicea: la crisis de la fe en Dios (Madrid: Editorial Trotta, S.A., 1997), 95-96.

${ }^{95}$ Estrada, La imposible teodicea, 97.

${ }^{96}$ García Castillo, Plotino (204/5)-270), 15.
} 


\section{Lo que "es" y lo que debe "ser" (a Platón y a Plotino)}

Este ensayo desarrolla la idea teosófica sobre que existe una conciencia divina que dirige todos los acontecimientos del mundo, pero además que esta no está satisfecha con el mundo tal como es. Dios para ellos, es un reformador que constantemente está haciendo planes para mejorar el mundo, a este proceso le llaman: evolución, por lo tanto, de ser esto cierto, para ellos existe una interacción entre dos realidades, "el mundo tal como es" (imperfecto) y "el mundo como debe ser" (perfecto) ${ }^{97}$, que es lo que Jinarajadasa concebía como un "mundo arquetípico". Esta clasificación fue la misma que hicieron los filósofos platónicos al dividir la realidad en "mundo visible" y "mundo intangible"

Para los teósofos, el mundo del "deber ser" ejercía acción sobre el mundo del "ser". Para llegar al mundo del "deber ser" existían muchos caminos entre los cuales estaban: la poesía, la escultura, la pintura, la música y la arquitectura, en fin, todo artista que se sentía estimulado a describir el mundo no como "era" sino tal y como debía ser. Los artistas, por tanto, tenían vislumbres de ese otro mundo. Según Jinarajadasa, en cada uno de nosotros habita un artista que espera a ser libertado y revelado, porque Dios habita en todos y es el Supremo Artista (Arquitecto). Todo artista es consciente de que existe una perfección en su arte, y lo que él realiza está cerca de esa perfección, en cambio, las personas comunes y corrientes, según el teósofo, hacen arte al hacer algo perfecto, ya sea en forma de pensamiento o acción. La perfección radica en la calidad de estos ${ }^{99}$ :

Un callado pensamiento de amor perfecto o de ternura, un acto aunque sea pequeñito de sacrificio; una lucha por algo puro y noble aunque no llegue nunca a ser conocido, todas estas son ocasiones cuando el artista que está dentro de nosotros proclama como ha visto al mundo tal y como debe de $\operatorname{ser}^{100}$.

Para Jinarajadasa, la imaginación era lo que entretejía el mundo del "ser" y del “deber ser". Lo que "debía ser" siempre estaba tratando de fundirse con lo que "es", porque el universo siempre está siendo modelado por su arquitecto a efecto de que este pueda reflejar una última perfección, es decir, un mundo arquetípico que es la meta final hacia la

\footnotetext{
97 Diario Oficial, Suplemento La República, "Disertación sobre temas filosóficos del Señor General Hernández Martínez", 11 de diciembre de 1942, 4. "En cada uno de nosotros existe una doble personalidad: lo que somos y lo que deseamos ser. En el interior de cada uno de nosotros lucha la perfección y la imperfección. El problema se reduce por consiguiente a saber de qué lado se encuentra la verdad, si no lo averiguamos con exactitud y precisión, continuará existiendo en el hombre aquella dualidad y entonces el espíritu ira de un lado a otro como sin brújula...la manera de resolver aquella dualidad y de mantener latente en todos la verdad única que es el bien, no estriba en contener la emoción del mal sino en transmutarla".

98 Jinarajadasa, "Lo que "es" y lo que debe "ser" a Platón y a Plotino", Diario Oficial, Suplemento La República, 23 de septiembre de 1942, 2.

99 Jinarajadasa, "Lo que "es" y lo que debe "ser" a Platón y a Plotino", 2.

100 Jinarajadasa, "Lo que "es" y lo que debe "ser" a Platón y a Plotino", 2.
} 
cual toda la creación está encaminada. En todo caso, nuestro "ser" era una derivación del "ser" absoluto y nuestro descenso de él hacia la encarnación era semejante a la caída de una bola que estaba atada por una cuerda elástica desde un punto en lo alto. En el momento que la bola caía en el vacío se producía una tensión que la atraía todo el tiempo, por lo que esta trataba de retornar hacia su longitud normal u origen ${ }^{101}$.

Según Jinarajadasa, el ser humano más que la verdad, debía buscar la perfección en cuanto pensamiento, palabra y acción. Esta búsqueda es lo que lo llevaría a evolucionar hasta llegar al escalafón más alto, ya que como es obvio advertir la teosofía toma del neoplatonismo su concepción de las varias escalas del "ser"102. Otro camino era el amor que se manifestaba cuando el amante doblaba sus rodillas ante el amado y exclamaba ¡mi Señor y Dios! A otros se les manifestaba mediante la revelación de un "mensaje", ya fuera de un maestro, un salvador o un gurú como Cristo o Buda, pero todos estos caminos tendían a formar una "unidad" que en el espacio y en el tiempo, se manifestaban mediante una dualidad; dualidad que, al final, era trascendida al encontrar a Dios.

Para Jinarajadasa, el hombre no alcanzaría la perfección mientras no aprendiera a ser noble, heroico y solidario. El que había llegado a conocer el "debe ser" jamás volvía a doblar sus rodillas a lo que "es", podía soportarlo y tolerarlo, pero no volvía a entrar nunca en la oscuridad donde sólo hay débiles resplandores de luz, donde se busca la luz y los demás no son nada más que sombras ${ }^{103}$. Todo esto en claro parafraseo al mito de la caverna de Platón.

Debemos recordar también que en el campo de las relaciones humanas el "deber ser" es la ética, la cual desde las concepciones platónicas aleja de lo sensible y acerca a lo divino $^{104}$. Finalmente se verán las soluciones que la teosofía aporta a los problemas materiales del mundo.

\section{Un Mundo Angustiado}

La influencia de Jinarajadasa desde los inicios de la presidencia de Martínez fue mucho más relevante que la de Krishnamurti, ya que desde 1933 se publicaron en medios oficiales sus impresiones sobre cuestiones teosóficas como las obtenidas en la Primera Convención Mundial de la Sociedad Teosófica celebrada en la ciudad de Adyar, India, el 24 de diciembre de $1932^{105}$. En esta, Jinarajadasa explicó que los teósofos no tenían una creencia o religión en común sino solo la de crear una "fraternidad universal" de la

\footnotetext{
${ }^{101}$ Jinarajadasa, "Lo que "es" y lo que debe "ser" a Platón y a Plotino", 24 de septiembre de 1942, 2.

${ }^{102}$ García Castillo, Plotino (204/5)-270), 46.

${ }^{103}$ Jinarajadasa, "Lo que "es" y lo que debe "ser" a Platón y a Plotino", 2.

${ }^{104}$ García Castillo, Plotino (204/5)-270), 26.

105 Jinarajadasa, "Un mundo angustiado: primera conferencia de la convención de la Sociedad Teosófica Mundial, celebrada en Adyar, Madras, India el 24 de diciembre de 1932", Diario Oficial, Suplemento La República, 5 de noviembre de 1933, 2-3.
} 
humanidad, pero el hindú explicó que a la teosofía no solamente le interesaban las cuestiones especulativas sino que también las materiales ${ }^{106}$ :

Ser teósofo, quiere decir, sentir agudamente toda desgracia que aflija a la humanidad y ser reformadores, tratando siempre de saber de qué manera podemos disminuir las miserias del mundo. Nuestro primer deber como teósofos es ir por el mundo tratando de abolir o disminuir el sufrimiento, donde quiera que lo encontremos. Para guiarnos en la realización eficaz de esta obra, disponemos de una gran masa de ideas llamadas teosofía ${ }^{107}$.

Jinarajadasa fue muy tajante al decir que ninguno de los miembros de la Sociedad Teosófica estaba obligado a aceptar lo que la teosofía proclamaba sino más bien creía que cada teósofo debía escoger dentro de sus enseñanzas, las que más le parecieran útiles. Jinarajadasa también habló sobre los efectos de la crisis económica mundial de 1929, pues, tuvo su punto más álgido en 1932. Describió todo el descalabro financiero provocado y como los grandes economistas del mundo se vieron en serias dificultades para restablecer la situación $^{108}$.

Pensaba que todos le atribuían distintas casusas a la crisis y por lo tanto, propusieron distintas soluciones. Unos sugirieron el cambio del sistema bancario, otros la abolición de las tarifas aduaneras y así por el estilo, pero Jinarajadasa estableció que el problema de raíz radicaba en un cambió sutil que se había verificado en el mundo, con respecto a lo que era digno de seguir en la vida que, según él era: "lo recto, lo bello y lo bueno", pero que debido al positivismo esta actitud se estropeó ${ }^{109}$.

La ciencia, según sus apreciaciones, durante los últimos cincuenta años había producido un gran progreso en la humanidad, sobre todo, por el gran desarrollo de la maquinaria y la producción de objetos que facilitaban la vida cotidiana, pero creía que esto trajo como efecto contraproducente el deseo de satisfacer necesidades "creadas", es decir, se construyó un sistema artificial para que la gente pensara que no podía ser feliz si no tenía

\footnotetext{
${ }^{106}$ Diario Oficial, Suplemento La República “Comentarios al mensaje Presidencial”, 22 de febrero de $1941,1$. "Dice el Jefe Supremo del Estado en su importante mensaje que en la formación del hombre hay que atender de preferencia la formación del cuerpo físico, de su cuerpo mental y de su cuerpo espiritual. Que corresponde a la economía nacional la preparación de los medios necesarios para que las subsistencias sean suficientes para la alimentación y sanidad de los hombres y corresponde al ramo de educación la preparación mental e intelectual de los ciudadanos (...) mediante la fraternidad y la ayuda mutua se dará solución a los problemas de orden económico y mediante la acción de instrucción pública será posible la renovación de las ideas en el globo terrestre".

107 Jinarajadasa, "Un mundo angustiado", 2-3.

108 Jinarajadasa, "Un mundo angustiado", 2-3.

109 Jinarajadasa, "Un mundo angustiado", 2-3.
} 
aquel o este objeto. Jinarajadasa criticaba la actitud consumista y materialista que había conllevado la ciencia y el uso frívolo que había hecho el sistema capitalista de la técnica ${ }^{110}$.

El problema fundamental para Jinarajadasa era que las naciones estaban organizadas en función de vender y comprar artículos tan pronto como fuere posible, lo comercial había privado por sobre lo espiritual y lo cultural, produciéndose así una plétora de productos superior a las que el mundo realmente necesitaba, lo que desencadenó una competencia morbosa de la gente en el afán superfluo de adquirirlos ${ }^{111}$. El lema de los economistas era: "debemos crear más dinero para todos, a fin de que se puedan crear más productos" "112.

La solución a la crisis económica mundial, para él, era crear un ambiente más espiritual y es por eso, que retomó el adagio chino: "si tienes dos panes, vende uno y cómprate un lirio," el cual era un principio espiritual para empezar a transformar la vida colectiva $^{113}$. Era necesario crear, entonces, entre la gente una nueva conciencia que les permitiera diferenciar entre lo esencial y lo transitorio con el objeto de que dejaran de sufrir por lo banal y esto es, quizás, a lo que Gramsci llamaba una filosofía popular, es decir, un arte popular de saber vivir.

Para Jinarajadasa, la solución al problema económico consistía en que una minoría en cada país de la Tierra debía luchar por cultivar lo espiritual, si se lograba esta misión la maquinaría del aparato de producción - de forma automática- se volvería a reajustar, disminuyendo así las luchas al interior de los pueblos y entre países. En esto consistía la solución para el mundo angustiado de esa época ${ }^{114}$.

\footnotetext{
${ }^{110}$ Diario Oficial, Suplemento La República, "La plática del martes último del General Martínez", 19 de diciembre de 1942, 4. "La disertación del mandatario salvadoreño versó alrededor de las posesiones materiales, insaciable sed que corrompe a los individuos y extensivamente a algunos pueblos quebrantando así los ideales de pureza espiritual y el anhelo de felicidad de quienes piensan en Dios y buscan por derroteros de elevados sentimientos de "regeneración" la perfectibilidad humana".

${ }^{111}$ Diario Nuevo, "Plática del Presidente General Martínez", 12 de febrero de 1941, 1-2. "Los hombres de algunas naciones ambicionaron para su patria la mayor riqueza, el mayor poder. Se dijeron a sí mismos: necesitamos mercados para vender los productos que elaboramos y materia prima que sirva de base. Como por este camino se llega al cruento dolor de la guerra, a la devastación y a la miseria, es necesario que busquemos una solución al problema (...) son pocos los hombres que piensan en que la solución del problema está en servir en vez de que nos sirvan".

112 Jinarajadasa, "Un mundo angustiado", 2-3.

113 Jinarajadasa, "Un mundo angustiado", 2-3.

${ }^{114}$ Jinarajadasa, "Un mundo angustiado", 2-3.
} 


\section{Imagen 4}

Foto de prensa: Jinarajadasa en San Salvador, El Salvador

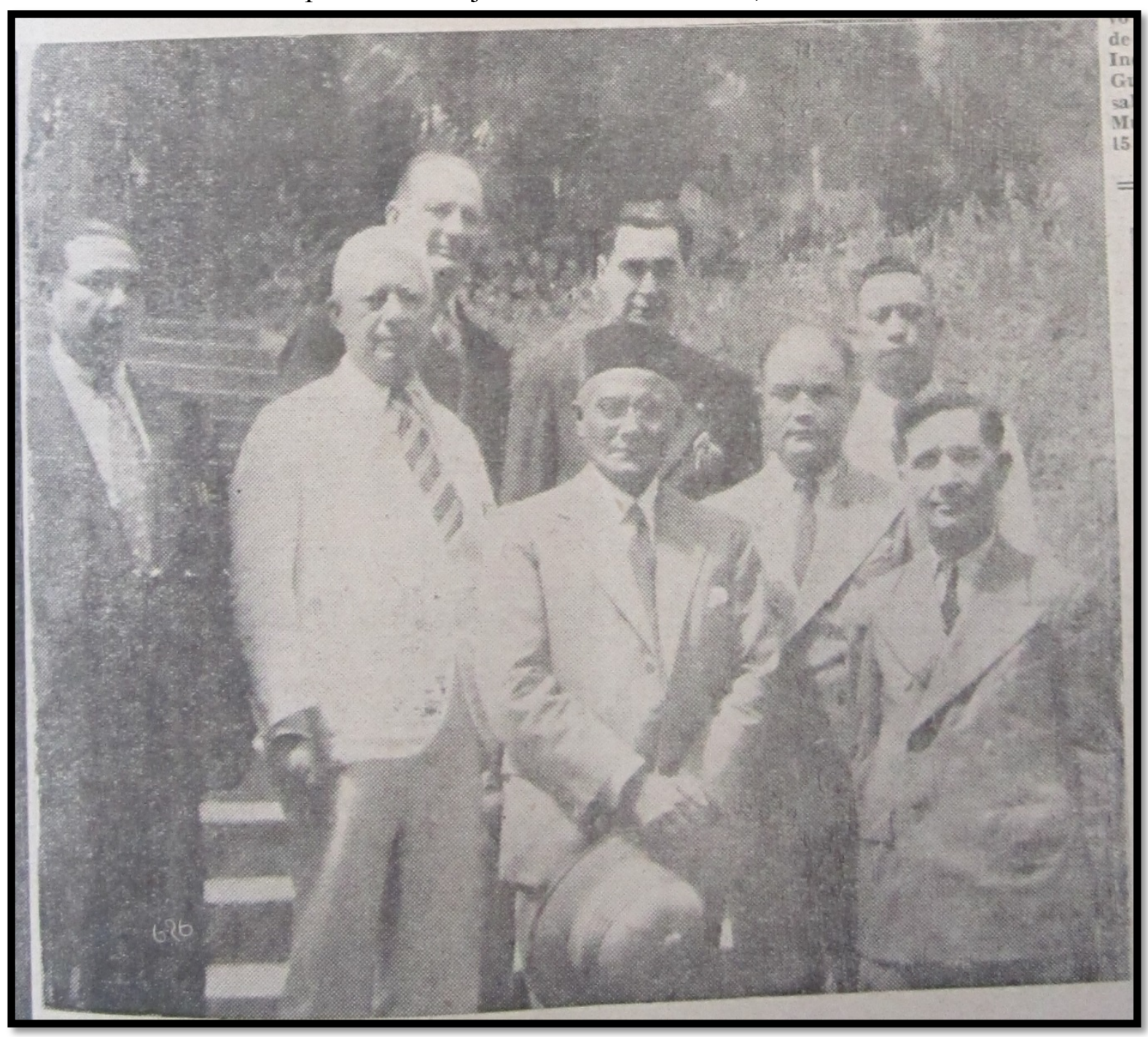

El periódico El Diario de Hoy fotografió a Jinarajadasa en la quinta Ungo, colindante con el asilo Sara, San Salvador. En la foto se pueden observar a algunos miembros del comité que lo atendieron en la capital salvadoreña.

Fuente: "Fotografía de Carlos Jinarajadasa en El Salvador", El Diario de Hoy, 29 de octubre de 1938, 1.

\section{Partida de Jinarajadasa de El Salvador y su recepción en Guatemala}

A pesar de que la estadía de Jinarajadasa en El Salvador fue por muy pocos días la teosofía tuvo en gran despliegue en los medios periodísticos de ese tiempo. Jinarajadasa partió para Guatemala el 28 de octubre de 1938 y llegó ese mismo día; la última conferencia que impartió en El Salvador fue Los agentes de Dios: los niños. Antes de su 
partida pronunció una conferencia (cerrada) únicamente para los miembros de las logias salvadoreñas. La Sociedad Teosófica de Guatemala también hizo gestiones por medio de su Presidente Facundo Roch ${ }^{115}$ para que Jinarajadasa visitara aquel país en el cual fue recibido por algunos miembros de dicha logia, entre los cuales se encontraban: Osberto Wyld Ospina, Segundo de la Rocha, Alejandro Serovic y Alejandro Baldizón. Dicha sociedad solicitó al periódico independiente El Imparcial hacer una amplia invitación al público capitalino, especialmente, a los elementos de la intelectualidad guatemalteca para que acudiesen a escuchar al orientalista ${ }^{116}$.

En Guatemala hubo un amplio sector con interés de escucharlo, sobre todo en los departamentos de Huehuetenango, San Marcos, Retalhuleu, Mazatenango y la villa de Coatepeque; finalmente dictó sus conferencias en el local de la Academia Práctica Comercial y en la Metrópoli Altense de la capital. También desarrolló algunas pláticas en Quetzaltenango en donde los teósofos Nicolás Sieckawizza y Rafael A. Recinos hicieron esfuerzos por conseguir el Teatro Municipal no siendo posible, por lo que fue huésped por pocas horas de la familia Sieckawizza, dictando sus conferencias en el amplio patio de su casa.

Al parecer fue un numeroso auditorio el que concurrió, quedando la impresión que este improvisado local fue, al final, mucho mejor que el teatro. Jinarajadasa habló, especialmente, de la obligación que tenían los padres de mandar a sus hijos a la escuela, de la necesidad de inculcar los buenos hábitos y guardar el debido respeto hacia los padres, maestros e instituciones patrias ${ }^{117}$.

\section{Conclusión}

La segunda gira latinoamericana de Jinarajadasa fue todo un éxito si la comparamos con la gira que Krishnamurti había tenido hacía unos años antes en 1935. Da la impresión que el público en general estaba mucho más familiarizado con las enseñanzas teosóficas y es notorio que los medios escritos hicieron mucha más publicidad de una forma más sistematizada que en 1929, por lo que la recepción de las conferencias de Jinarajadasa fue mucho mejor. Es ineludible mencionar que el hecho de que Maximiliano Hernández Martínez se encontrará en el poder favoreció el ambiente, pero también es cierto que había todo un engranaje intelectual que lo impulsaba.

Cabe decir que muchas logias teosóficas latinoamericanas mandaron a imprimir las referidas conferencias y las hicieron circular con mucha fuerza; en Costa Rica, por ejemplo fueron organizadas por el centro de estudios teosóficos Virya primera logia fundada en

\footnotetext{
${ }^{115}$ Cronos, "El ilustre Dr. Jinarajadasa llegará en breve a Guatemala", 6 de septiembre de 1938, 1.

${ }^{116}$ El Imparcial, "Jinarajadasa llega mañana", 27 de octubre de 1938, 1.

${ }^{117}$ El Liberal Progresista, "El teósofo Jinarajadasa dictó conferencias en Quetzaltenango", 9 de noviembre de 1938, 11.
} 
Centroamérica el $1^{\mathrm{o}}$ de junio de 1904 y radiotransmitidas por la estación Athenea ${ }^{118}$. Definitivamente tanto las conferencias de 1929 como las de 1938 movieron poderosamente el ambiente intelectual y social latinoamericano. Cuando se leen comentarios sobre el número de personas que asistían a las pláticas de 1938 casi siempre se suele encontrar que las salas, los teatros y los demás locales donde disertaba el hindú se abarrotaban. Un punto interesante de dichas conferencias es que a pesar de que mantenían una línea predominantemente teosófica, también abordaban distintos problemas de carácter coyuntural, teniendo un fuerte componente social debido a la depresión económica mundial.

Otro aspecto importante a destacar es que en Europa estaban surgiendo los nacionalismos políticos más radicales que ha vivido la historia de la humanidad: el fascismo italiano y el nacional-socialismo alemán y aunque varios autores han ligado los orígenes del nazismo con la difusión de la teosofía en el viejo continente, en esta parte del mundo se veía como el antídoto y la antítesis a dichas doctrinas ¿Por qué? Porque hacía llamamientos a la comprensión entre todas las naciones, razas y religiones. De más está decir que el nazismo promovió el odio de razas. Ahora bien, por otro lado, la teosofía también guardaba un carácter pacifista-espiritualista lo que la convertía en una alternativa al marxismo-leninismo beligerante y materialista, por eso no es accidental que la teosofía haya centrado gran parte de sus esfuerzos en el tema de la divinidad y, que tuviera como objetivo fundamental una especie de re-evangelización laica que erradicara el creciente ateísmo, pero que además superara las divisiones causadas por las religiones tradicionales.

Es por eso que no resulta exagerado decir que la teosofía, según sus simpatizantes latinoamericanos, era la doctrina que evitaría que la civilización fuera a dar con el traste y en ese sentido, la opinión pública se mostraba muy favorable a ella. En este contexto el libro La Decadencia de Occidente de Oswald Spengler, es un reflejo del sentir y el pensar de una época en la que se creía haber llegado al fin del proceso modernizador. En primer lugar, Spengler establece que el alma se convirtió en uno de los temas centrales a finales del siglo XIX porque se consideró era algo que no podía ser aprehendido por medios racionales, de ahí que la teosofía haya hecho mucho énfasis en la teoría de la metempsicosis de Platón y en la teoría de la reencarnación órfica-pitagórica y de las religiones orientales, ya que estas orbitaban alrededor de la inmortalidad del alma. El alma era algo que solo podía ser expresado por medio de imágenes, metáforas, representaciones y mitos y no en un idioma lógico o psicológico positivista ${ }^{119}$.

Spengler establece que el hombre a través del alma se proyecta y que toda teoría del alma constituye en sí un mito, es decir, la teosofía funciona en base a mitos y esto es muy normal, porque el positivismo se centraba en estudiar la naturaleza y su contrasentido sería

\footnotetext{
${ }^{118}$ El Cronista, "Vendrá a Honduras el Dr. Jinarajadasa", 10 de agosto de 1938, 1 y 8.

119 Oswald Spengler, La decadencia de Occidente, bosquejo de una morfología de la historia universal (Madrid: Espasa-Calpe Editores., 1948), 128-129.
} 
hacer un estudio antropológico fundado en el alma; según Spengler toda psicología no experimental es contra-física y he ahí la explicación de por qué la teosofía hizo un gran despliegue teórico para demostrar que era un absurdo pretender probar la existencia del alma a partir de una ciencia exacta ${ }^{120}$.

Esta actitud de la teosofía de abrirse a diferentes culturas orientales fue debido a que occidente había convertido la Tierra en una sola colonia y en un solo sistema económico: el capitalismo que ansiaba uniformarlo todo, incluso, lo estético y lo moral, y es por eso que surgió por parte de los círculos espiritualistas de América, un imperialismo de tipo no marxista y una resistencia al ultramontanismo ya que, precisamente, la decadencia de los valores occidentales tenía mucho que ver con la intolerancia de la Iglesia católica que quería imponer su moral de forma unilateral, y, por tanto, erradicar a todas aquellas doctrinas que constituyeran verdades alternativas tales como la teosofía y la masonería. ${ }^{121}$

Concluimos en base a las tesis spenglerianas que la teosofía nació como fruto de que la sociedad occidental moderna se volvió demasiado intelectualista, es decir, hubo un predominio de lo cerebral por sobre lo espiritual, por tanto, la consecuencia más importante de las conferencias de Jinarajadasa fue que ayudaron a crear una cultura latinoamericana más espiritual. Todos los sistemas filosóficos que habían sido creados hasta ese momento, se percibieron como artificiosos y desesperanzadores. En este sentido, aunque la teosofía formalmente sea considerada como una pseudo-filosofía, constituyó una nueva opción moral que también aportó un toque metafísico. Otras filosofías de este tipo para Spengler eran: el estoicismo y el budismo ${ }^{122}$. Estas tendencias llenaron el vacío y la frialdad que había dejado el intelectualismo, incluso, Spengler llegó a afirmar que el verdadero metafísico era aquel que veía a los números como símbolos y que Platón y Pitágoras fueron las cumbres del pensamiento antiguo. En la década de los treinta, lo ético se convirtió en el centro de lo filosófico porque declinaba la pasión hacia el pensamiento puro ${ }^{123}$.

\section{Fuentes primarias}

Cronos 1938.

Diario Latino 1938.

Diario Nuevo 1938, 1941, 1943.

Diario de Occidente 1938.

Diario Oficial, Suplemento La República 1933, 1938, 1941-1943.

El Cronista 1938.

\footnotetext{
${ }^{120}$ Spengler, La decadencia de Occidente, 130 y 133.

${ }^{121}$ Spengler, La decadencia de Occidente, 184, 188, 192, 193.

122 Spengler, La decadencia de Occidente, 205

${ }^{123}$ Spengler, La decadencia de Occidente, 225 y 226.
} 
El Diario de Hoy 1938.

El Imparcial 1938.

El Liberal Progresista 1938.

La Prensa 1933, 1938.

Patria 1929.

\section{Bibliografía}

Barlow, Michel. El pensamiento de Henri Bergson. Ciudad de México: Fondo de Cultura Económica, 1968.

Bergson, Henri. Memoria y vida, textos escogidos por Gilles Deleuze. Madrid: Alianza Editorial, S.A., 1977.

Aguiar Bobet, Valeria. "La seducción del esoterismo: masones y teósofos en el protectorado español de Marruecos”. Revista Melancolía 2 (2017): 78-103, http://www.revistamelancolia.com/index.php/melancolia/article/view/19/23

Carlyle, Tomas. ¡Trabaja y confia!, normas y consejos para la orientación de la vida. Barcelona: Editorial Ossó, 1930.

Casaús Arzú, Marta Elena. El libro de la vida de Alberto Masferrer y otros escritos vitalistas, Edición crítica de la obra teosófico-vitalista (1927-1932). Ciudad de Guatemala: F\&G Editores, 2012.

Casaús Arzú, Marta Elena. "La disputa por los espacios públicos en Centroamérica de las redes unionistas y teosóficas en la década de 1920: La figura de Alberto Masferrer". Revista Humanidades IV, no. 2 (2003): 51-77.

Casaús Arzú, Marta Elena. "El vitalismo teosófico como discurso alternativo de las élites intelectuales centroamericanas en la década de 1920 y 1930. Principales difusores: Alberto Masferrer, Carlos Wild Ospina y Porfirio Barba Jacob”. REMHLAC 3, no. 1 (mayo-noviembre 2011): 82-120, https://revistas.ucr.ac.cr/index.php/rehmlac/article/view/6588/6279

Devés Valdés, Eduardo. "Redes teosóficas y pensadores políticos latinoamericanos, 19101930". Cuadernos Americanos 6, no. 78, (1999): 137-152.

Estrada, Juan Antonio. La imposible teodicea: la crisis de la fe en Dios. Madrid: Editorial Trotta, S.A., 1997.

García Castillo, Pablo. Plotino (204/5)-270). Madrid: Ediciones del Orto, 2001.

Lara-Martínez, Rafael. Del silencio y del olvido o los espectros del patriarca. San Salvador: Fundación AccesArte, 2013.

Mejía Burgos, Otto German. "La teosofía en algunos periódicos salvadoreños y centroamericanos durante las décadas de 1930 y 1940”. REHMLAC+ 9, no. 2 
(diciembre 2017-abril 2018): 220-250, https://revistas.ucr.ac.cr/index.php/rehmlac/article/view/30538/31664

Rodríguez-Dobles, Esteban. "Redes esotéricas en Centroamérica y Colombia (1904-1940). El caso de la Sociedad Teosófica”. Revista Melancolía 1 (2016): 75-106, https://revistas.ucr.ac.cr/index.php/rehmlac/article/view/6588/6279

Rúskin, John. El hombre y la naturaleza. Madrid: Editorial Espasa-Calpe, 1933.

Spengler, Oswald. La decadencia de Occidente, bosquejo de una morfología de la historia universal. Madrid: Espasa-Calpe Editores., 1948. 